Portland State University

PDXScholar

1990

\title{
The relationship between reading comprehension and self-esteem in low level reading adults
}

Judy Rosen Heumann

Portland State University

Follow this and additional works at: https://pdxscholar.library.pdx.edu/open_access_etds

Part of the Education Commons

Let us know how access to this document benefits you.

\section{Recommended Citation}

Heumann, Judy Rosen, "The relationship between reading comprehension and self-esteem in low level reading adults" (1990). Dissertations and Theses. Paper 4180.

https://doi.org/10.15760/etd.6064

This Thesis is brought to you for free and open access. It has been accepted for inclusion in Dissertations and Theses by an authorized administrator of PDXScholar. Please contact us if we can make this document more accessible: pdxscholar@pdx.edu. 
AN ABSTRACT OF THE THESIS OF Judy Rosen Heumann for the Master of Science in Education presented November 7, 1990.

Title: The Relationship Between Reading Comprehension and Self-Esteem in Low Level Reading Adults.

APPROVED BY THE MEMBERS OF THE THESIS COMMITTEE:

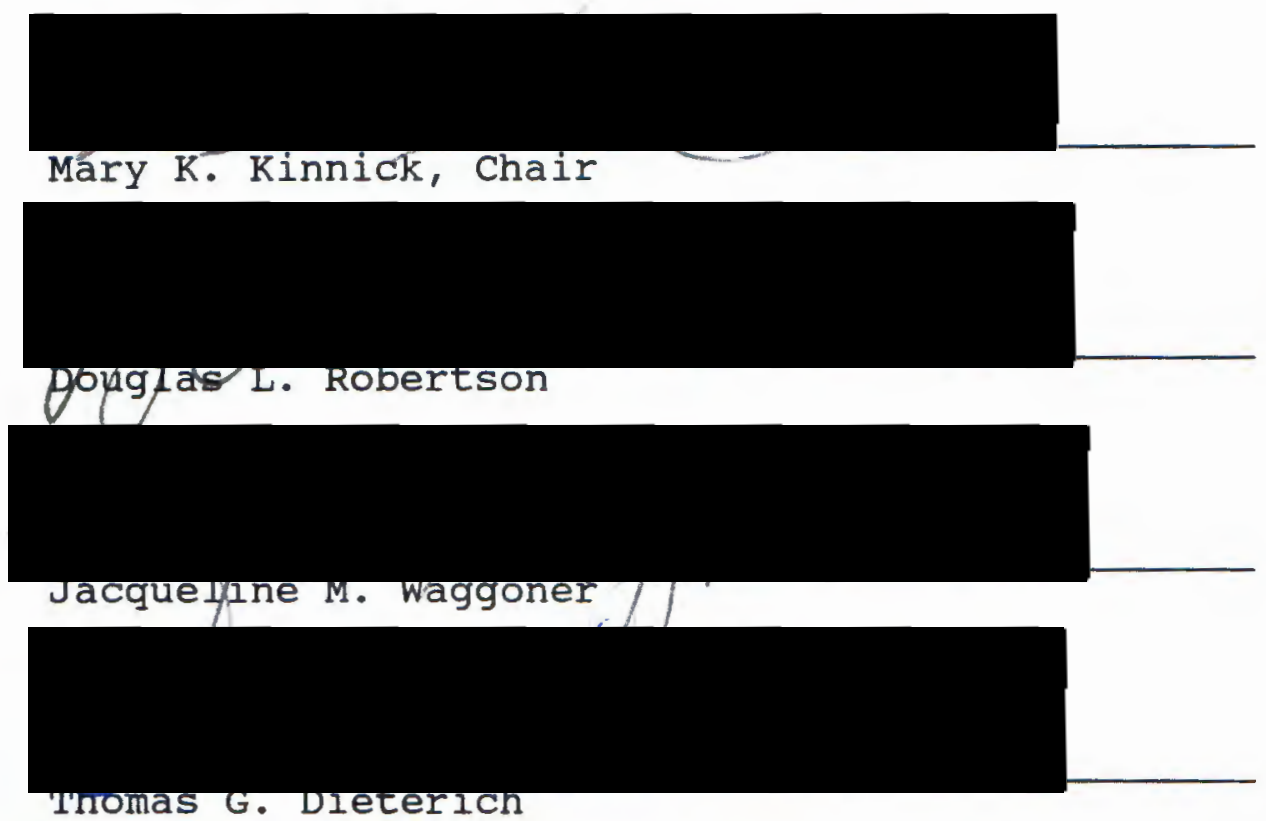

The purpose of this study was to determine if a correlation existed between reading comprehension and selfesteem in adults with no reading ability to adults reading at the fifth grade level. Reading comprehension was measured by the comprehension section of the Brigance Diagnostic Comprehensive Inventory of Basic Skills in half year increments after primer level, from lower first to upper third grade. Full year increments were indicated from 
fourth through ninth grade. Self-esteem was self-reported through use of the Counseling form of the Tennessee self Concept Scale. Data were collected during Fall term, 1989 (September through December) at Portland Community College, Southeast Center in an Adult Basic Education class. T-tests indicated that both reading comprehension and some aspects of self-esteem rose through the study period. However, using the Pearson correlation coefficient, it was determined that a significant correlation did not exist between the variables in question. 
THE RELATIONSHIP BETWEEN READING COMPREHENSION AND SELF-ESTEEM IN LOW LEVEL READING ADULTS

JUDY ROSEN HEUMANN

A thesis submitted in partial fulfillment of the requirements for the degree of

\author{
MASTER OF SCIENCE \\ in \\ EDUCATION
}

Portland State University

1991 
TO THE OFFICE OF GRADUATE STUDIES:

The members of the Committee approve the thesis of Judy Rosen Heumann presented November 7, 1990.
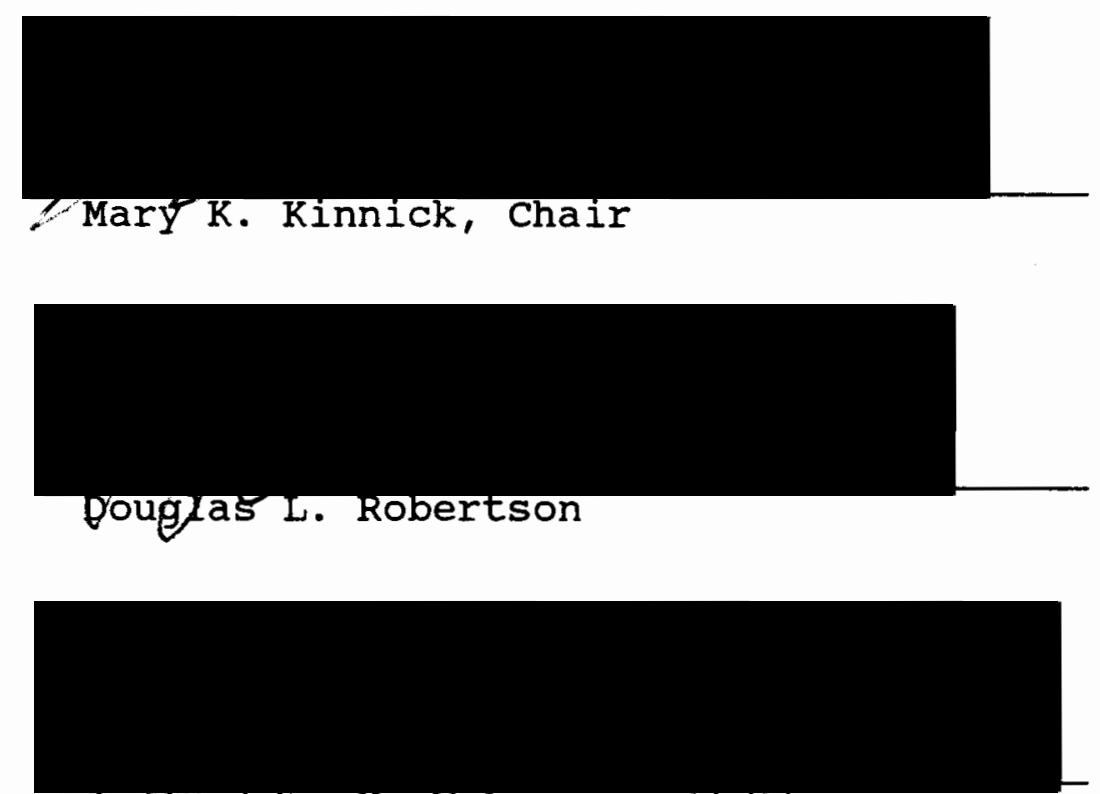
Jacquerfne $\mathrm{M}$. waggoner //

Inomas G. Dleterlch

APPROVED.

Robert B. Everhart, Dean, School of Education

C. William Savery, Interim Viqejprovost for Graduate studies and Research 


\section{ACKNOWLEDGEMENTS}

I am sincerely grateful to the members of my committee, Chairperson Dr. Mary Kinnick, Dr. Doug Robertson and Dr. Jackie Waggoner, for their guidance and assistance throughout my project. The vision for me to sustain my enthusiasm to see this study through to completion was provided by their words of encouragement.

Dr. Larry Rosen was instrumental in his assistance with the data analysis. Technical assistance was graciously provided by Jamie Meyers.

To my children, Joshua and Lauren, I want to say thank you for being patient through the process of my work. Above all, I wish to acknowledge my appreciation to my husband, Michael, who not only provided on-going support in the darkest hours, but who also shared his invaluable technical expertise. 
TABLE OF CONTENTS

PAGE

ACKNOWLEDGEMENTS........................

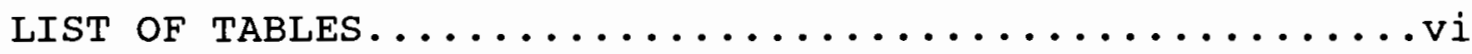

CHAPTER

I INTRODUCTION......................

Statement of the Problem.............

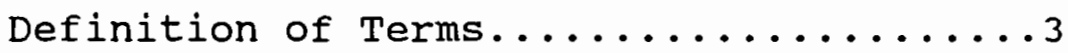

II REVIEW OF THE LITERATURE............

Adult Literacy.................

Definition of Self-Esteem..........

Factors Influencing Self-Esteem.......11

Undereducated Adults, Self-Esteem

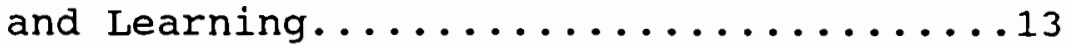

Self-Esteem and other Special

Characteristics.................19

Hearing Impairment

Employment

Theory and Research: Self-Esteem

and Achievement.................... 24

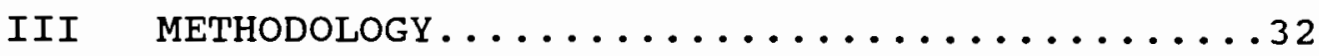

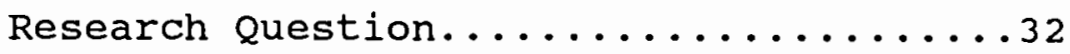

Hypothesis........................ 32

Study Design, study setting,

and subjects....................... 32

Instrumentation................. 35 
Tennessee Self concept Scale Brigance Comprehensive Inventory of Basic Skills

Demographic Survey

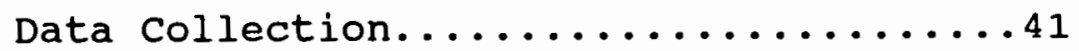

Data Analysis.................... 43

Limitations..................44

Tennessee Self Concept Scale

Brigance Comprehensive Inventory

of Basic Skills

Design Concerns

IV $\quad$ RESULTS........................

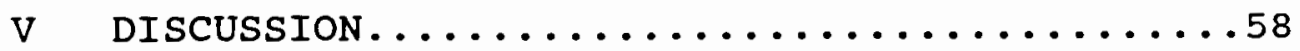

Interpretation............... 58

Conclusions and Recommendations......6. 62

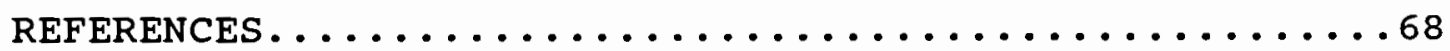

APPENDICES

A SELF-REPORTED STUDENT PROFILE..........74

B TENNESSEE SELF CONCEPT SCALE AND

ANSWER SHEET.....................

C TEST-RETEST RELIABILITY OF MAJOR

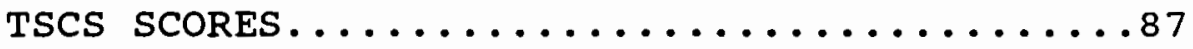

D BRIGANCE COMPREHENSIVE INVENTORY OF

BASIC SKILLS.................... 89

E DEMOGRAPHIC SURVEY....................

F INFORMED CONSENT.................. 108 
I Results of Demographic Survey............51

II Pre- and posttest Results of TSCS and Levels of Significance (Using a t-Test) ..53

III Correlation in Mean Scores Between Change in Total Positive and Change in Variability (Using Pearson Correlation Coefficient at .05 Level of Significance, $\mathrm{DF}=19) \ldots . . . \ldots . . . . . . .54$

IV Pre- and Posttest Results for Brigance Comprehensive Inventory of Basic Skills.....55

$\mathrm{V}$ Correlation in Mean Scores Between Change in TSCS and Change in Brigance Comprehensive Inventory of Basic Skills (Using Pearson Correlation Coefficient at .05 Level of Significance, $\mathrm{DF}=19) \ldots \ldots . . \ldots . \ldots . \ldots 56$

VI Demographic Correlations with Change in Total positive Scores and Reading Level (Using Pearson Correlation Coefficient at .05 Level of Significance, $\mathrm{DF}=19) \ldots . . . .57$ 
CHAPTER I

\section{INTRODUCTION}

Self-esteem, as a variable in the learning process, has been investigated in relation to a variety of educational issues. Researchers have taken a close look at the relationship between students' self-concept and their academic achievement. The set of attitudes that one holds about oneself and educational performance appear to be linked (Purkey, 1970; Burns, 1979; Thomas, 1980). There exists a wide body of literature examining the dynamics of the relationship between self-esteem and achievement, although the theoretical writings and empirical studies have been concerned primarily with school age children (Brookover \& Associates, 1964; Wirth, 1977; Marsh, 1984; Lawrence, 1985; Hadley, 1988). The correlation between self-esteem and achievement has not yet been tested with the population of low level reading adults.

Adult illiteracy is a growing problem. In 1969 the United States Bureau of Census stated that 1.4 milition people 14 years or older attended less than five years of school (cited in Jones, 1981). Each year, an estimated 2.3 million persons are added to that figure (U.S. Department of Education, n.d.). By 1983, the U.S. Department of 
Education reported that 23 million American adults were totally or functionally illiterate with an additional 23 million people functioning at a marginal level (cited in Kozol, 1985). Although methods to determine literacy to date have not been statistically standardized, a variety of sources confirm the severity and increasing nature of the problem (Harris, 1970, 1971; Northcutt, 1975; Hunter, Harman, 1979). Adult literacy programs are expanding to meet this need. In Oregon, Adult Basic Education enrollment has increased $304 \%$ from 1974 to 1988 (Oregon ABE Growth, 1987) •

Even though extensive research exists documenting the connection between self-esteem and achievement in the education of children, and evidence indicates that illiteracy among adult populations is increasing, more empirical information is needed concerning the operant issues of the adult illiterate population. As literacy programs grow, research determining the relationship between self-esteem and achievement will shed light on the degree to which these issues are significantly related in this population.

\section{STATEMENT OF THE PROBLEM}

Adults by definition, learning theory, and social research are responsible people who seek to build their self-esteem through pragmatic learning activities in which their competence is enhanced (Wlodkowski, 1985:6). 
In adults with low literacy skills, is self-esteem relational to an increase in reading comprehension as these adults seek to improve literacy skills? This question has yet to be examined with this increasingly visible adult subpopulation. The purpose of this study is to investigate the relationship between self-esteem and reading comprehension among low level reading adults in an Adult Basic Education class.

\section{DEFINITION OF TERMS}

Throughout the study there are several terms that deserve special clarification.

Adult Basic Education ( $A B E)$ is the term used in the federal Adult Education Act to describe education for adults at less than a high school equivalency level. Federallyassisted $A B E$ programs are offered in oregon through local community colleges and provide education to large and small groups of students using instructors and volunteers for delivery of instruction. The state of oregon provides additional funds through FTE (full time equivalency) payments to the colleges. Classes are free of cost to students.

Low level reading adults includes class participants ages 20 to 60 whose initial reading level ranged between no reading ability and fifth grade reading level. 
Reading comprehension is defined as the synthesis and understanding of written material. Half year grade level designations through the third grade and full year designations from grade level four through nine was indicated by the comprehension section of the Brigance Comprehensive Inventory of Basic skills.

Self-esteem. Self-esteem embodies the sense of evaluative self-worth. In seeking to capture the essence of this concept, subjects were asked to describe "how you feel about yourself" (Roid, Fitts, 1988:8) to yourself. Selfesteem will be measured by the counseling form of the Tennessee Self Concept Scale. 
REVIEW OF THE LITERATURE.

This chapter reviews the current literature pertinent to this study. The scope and extent of adult illiteracy illuminates the swelling ranks of low literate adults and a concomitant rise in participation in adult literacy programs. Self-esteem is defined, and the distinction is made between the concepts of "self-esteem" and "selfconcept". Adult self-esteem is addressed, and more specifically, self-esteem of undereducated adults in relation to learning, is examined. Two salient and observable characteristics of the study sample, employment status and hearing-impairment, is discussed in light of self-esteem. Lastly, theory and research regarding the connection between achievement and self-esteem leads to the purpose and design of this study.

\section{ADULT LITERACY}

The data concerning adult literacy rates are elusive due to an inconsistency in definitions of literacy and ways to measure it. In the past, grade level equivalencies were used. However, this proved to be an inadequate method of evaluation, because grade level completion does not 
guarantee that the subject actually reads at that level. Not only do grade level indications generally provide underestimates of abilities, in addition, this information does not indicate how long ago the grade level was obtained. Also, self-reporting of literacy information might yield inaccurate statistics (Jones, 1981:5-6). It was clear that indications of functional abilities or competencies to meet the current societal demands, rather than grade level completion, was needed.

Harris and Associates (1970) designed a study to determine the percentage of Americans lacking functional or practical reading skills. Using a reading measure of filling out application forms, the results of the survey indicated that from 4.3 to 18.5 million Americans were functionally illiterate. In 1971, Harris and Associates completed another study using different criteria. Telephone dialing instructions, classified employment, housing ads, and social benefit application forms required to qualify for a variety of public assistant benefits were used. Concluding observations indicated that $4 \%$ of the U.S. population (over 5.5 million people) 16 years of age and older "suffer from serious deficiencies in functional reading ability" (Harris, 1971:59).

The Adult Performance Level Project (APL) was a four year comprehensive study funded by the U.S. Office of Education in the 1970s (Northcutt, 1975). The study 
designed a series of real-world items to test functional competency by testing abilities in coping with the responsibilities of everyday life including communication skills (reading, writing, speaking, and listening), computation skills, problem solving skills, and interpersonal relationship skills. The U.S. Office of Education in applying the APL standards estimated that over $20 \%$ of the U.S. population (23 million) were unable to function adequately (cited in Kozol, 1985). A study funded by the Ford Foundation and published in 1979 reported that in 1978 there were between 54 and 64 million persons sixteen years and older who had not completed high school and were not currently enrolled in school (Hunter, Harman, 1979:28). Jonathan Kozol (Illiterate America) in conferring with both the directors of the APL and David Harman, proposed the following estimates for 1984: in terms of performance, not grade levels completion

[There are] 25 million people reading either not at all or at less than fifth grade level of competence; [and] 35 million additional persons reading at less than ninth grade level (Kozol, 1985:10).

The functional illiteracy rate continues to climb as societal literacy demands increase. An estimated 2.3 million persons annually join the ranks of the functionally illiterate (U.S. Department of Education, n.d.).

Participation in Adult Basic Education programs (ABE) has increased as the numbers of persons lacking basic skills 
has risen. Participation in Adult Basic Education programs in the United states rose by almost a million from 915,936 participants in 1980 to 1,910,003 participants in 1984 (U.S. Department of Education, 1986). In oregon, ABE enrollment in Oregon Community Colleges increased $304 \%$ from 9,616 in 1974 to 29,231 in 1988 (Oregon Adult Basic Education, 1988). Between the school years 1985-86 and 1987-88, there was a cumulative $35 \%$ growth in Level I (grades 0 to 8 ) $\mathrm{ABE}$ participation (Oregon ABE Growth, 1987).

\section{DEFINITION OF SELF-ESTEEM}

William James in 1890 delineated the significant parts of the self: the material self, or one's personal possessions including an individual's body, the social self, or the recognition received from others, and the spiritual self, or the inner subjective sense of being, ego, and consciousness of an internal and personal identity and worth (cited in Thomas, 1980). It is with the latter aspect that the concept of self developed. Coopersmith (1967) referred to a self evaluation that a person makes which indicates the extent of one's capabilities, significance, success, and worthiness. "In short, self-esteem is a personal judgment of worthiness that is expressed in the attitudes an individual holds" (Coopersmith, 1967:4). Burns stated simply:

[an] individual feels he is a person of worth, respecting himself for what he is, not 
condemning himself for what he is not, and the extent to which he feels positively about

himself. Low self esteem suggests self rejection, self derogation and negative self evaluation (Burns, 1979:55).

As an important psychological construct in explaining or predicting behavior, self-concept embodies the notion of a person's self perceptions (Shavelson et al., 1976:411). Formed through one's interaction with the environment and significant others, self-concept is defined by Shavelson in seven features conceptualizing its meaning. Briefly stated, the self-concept is organized and structured. Secondly, it is multifaceted. The third feature implies that the selfconcept is hierarchical and based on individual experiences. A fourth feature states that the self-concept is stable, that is, it seeks to maintain itself as it exists. Fifth, is the developmental aspect of self-concept, especially in reference to the growth and development of children. A sixth feature of self-concept allows for differentiation from other constructs such as reasoning. Lastly, is the connection that Shavelson draws between self-concept and self-esteem. This feature of the self-concept typology highlights the sense of evaluation. Noting the interchangeability in past literature between the terms self-concept and self-esteem, Shavelson reflected on the nature of self-evaluations made in relation to social situations, expectations of self, or in regards to the standards of others. 
The evaluative dimension can vary in importance for different individuals and also for different situations" (Shavelson, 1976:411-415).

Throughout the literature, the terms "self-concept" and "self-esteem" have been used interchangeably (Wylie, 1961; Coopersmith, 1967; Shavelson, 1976; Burns, 1979; Hansford, Hattie, 1982). However, the distinction between the two words is important to note. "Self-concept" is an organized, composite set of regulated attitudes representing the self as it exists consistently (Burns, 1979:57). It is a generalization of the formation of the person's self. This complex dynamic has behavioral manifestations, which continues to define and support (either positively or negatively) the sense of "self" (Purkey, 1970; Yamamoto, 1972; Burns, 1979). "Self-esteem," as a sub-set of attitudes, adds the component of evaluation to the selfconcept. Self-esteem attaches evaluative self-perceptive judgments of worth and respect based on how a person views him- or herself. Self-esteem is under scrutiny as personal evaluative judgments are made regarding goals, levels of achievement, moral views, and social behavioral norms. "Self esteem means something like having faith in the self and letting the self concept settle where it belongs, not the other way around" (Yamamoto, 1972:214). 
FACTORS INFLUENCING SELF-ESTEEM

Adult self-esteem is a complex issue influenced by multiple factors and framed by a sense of past experiences and relationships. Firstly, the subject of adult selfesteem will be discussed in its broad context, and secondly, self-esteem of undereducated adults in relation to learning will be examined in more depth.

An issue of contention regarding adult self-esteem is whether to refer to the self as an object or as a process. Knox (1977) addressed this issue by examining typical sources of adult security--beliefs, family, friends and achievement. The sense of self, Knox contended, evolves throughout life, while reflecting the many influences of experiences and life roles. As the sense of self becomes more stabilized through successful life occurrences, single failures have less direct influence on self-esteem, either positively or negatively. This process of developing a sense of self is interrupted by the discrepancy between one's actual self and ideal self. The hiatus or gap provides the stimulation for continued growth.

The positiveness of self-concept and level of self-esteem tends to increase until middle age and then to stabilize or gradually decline (Knox, 1977:330).

Knowles (1970:44) viewed adult self-concept in comparison to self-concept theory of children. Knowles stated "the single most critical difference between children 
and adults as learners is the difference in assumptions we make about their self-concepts". Children begin life as dependent beings, taken care of by adults. The dependency concept is reinforced until the child begins to develop a sense of self identity. As a child grows and matures, he or she increasingly views the sense of self as independent and self-directing. The adult is "one who has arrived at a self concept of being responsible for one's life, of being selfdirecting" (Knowles \& Associates, 1984:9).

Refuting the assumption of self-directedness in adults, Brookfield (1986:94-95) purported that being an adult and arriving at a state of self-directedness are not automatically simultaneous occurrences. Rather, selfdirectedness is desirable, but cannot be an assumption in adults. In the learning environment, due to dependent-type past experiences with formal education, the opposite might be true. Adults might expect to be directed, rather than to exert their self-directedness, in the learning situation.

Examining the undereducated adult, Bowren and zintz (1977:20) suggested the theory that failure to achieve minimum standards of high school equivalency creates low self-concept and guilt. This segment of the population that seeks to upgrade literacy skills has a clear understanding of the skills it lacks. The undereducated adult perceives him- or herself as unacceptable as a learner, and as a result, undesirable as a person. 
UNDEREDUCATED ADULTS, SELF-ESTEEM AND LEARNING

Knowles contended that adult learners no longer view themselves as learners. At this place in life, adults derive their sources of fulfillment in their status as producers: workers, spouses, parents. When adults enter the learning environment, they bring with them recollections of their previous experiences as learners. For the undereducated adult, this might include uncertainties concerning academic abilities and aversion to the physical classroom space (Knowles, 1970:40).

The sense of uncomfortability in the learning environment is echoed throughout the literature (Imel, Grieve, n.d.; Bowren, Zintz, 1977; Darkenwald, 1980) and is manifested by a fear or anxiety of failure. Fingeret documented that undereducated adults describe themselves as concerned about their abilities to succeed in their attempts to improve their literacy skills (Fingeret, 1984). "This usually is interpreted as a psychological characteristic labeled variously fear of failure or low self-esteem and is attributed to the individual" (Fingeret, 1984:16).

In addition to a fear of failure, new learning implies change (Kidd, 1959). Kidd theorized that behavioral changes accompany new learning, and as a result, changes in selfconcept occur. The learner can behaviorally change, however, this new sense of identity or self must be both acceptable and defendable (Kidd, 1959). 
A middle class perspective has previously characterized the illiterate adult (Fingeret, 1984). From a middle class normative view point, the uneducated adult is compared and classified in light of a deficit perspective. The undereducated adult may be characterized as inarticulate, and unable to cope or think abstractly (Fingeret, 1984). Moreover, this population is globally considered dependent and incompetent by the literate society (Fingeret, 1983). other unempirical observations define uneducated adults as not being able to read at all, unknowledgeable about many issues, and unable to participate in life's activities (Reder, Green, 1985:7).

Contrary to this perspective is a more balanced view that considers that undereducated adults have learned through a broad background of life experiences (Jones, 1981, Fingeret, 1984) and have well-developed skills of all kinds, as well as a variety of strategies for coping with written material (Fingeret, 1983). Multiple life roles have enabled this population to acquire social skills and develop oral language patterns (Jones, 1981, Fingeret, 1983). Fingeret (1983) studied 43 adults in a mid-size, northeastern, urban setting and noted that illiterate adults create social networks that include readers and non-readers. Adults who are regarded by others as deficient may not regard themselves as such. They view themselves as interdependent, maintaining reciprocal relationships. The conclusion of 
this study indicated that illiterate adults have developed a large range of strategies designed to cope with the social world (Fingeret, 1983:145).

Mainstream coping strategies coupled with low level academic skills can have advantageous or disadvantageous manifestations in light of the undereducated adult. Previously acquired attitudes, values, and behaviors are difficult to change (Kidd, 1959). Prior negative interactions with formal schooling can cause adults to suffer from a negative view of him- or herself as a learner. A lack of confidence and continued avoidance of school experiences typifies the undereducated learner. Frustrations arising from slight barriers in the course of study confirm inabilities (Jones, 1981).

In discussing possible factors producing high fear or anxiety levels in undereducated adults, Bowren and zintz point to a potential threat to self-concept from inadequacies, causing adults to underestimate their abilities (Bowren, Zintz, 1977:42).

Because disadvantaged adults have rarely experienced success either as children in school or in their work or social life since leaving school, they often feel inadequate, unable to learn and compete (National Association for Public School Adult Education, 1966).

However, due to prior life experience, understanding of relationships and priorities, adults seeking to upgrade skills can be well motivated for the task. This population, 
in seeking to improve their quality of life, is dedicated to success and is stimulated by learning and behavioral goals (Jones, 1981:26).

In examining barriers or deterrents to education in low literate adults, Hayes (1988) studied a population of 160 low literate $A B E$ students (reading at or below sixth grade level) in seven urban $A B E$ programs. The $A B E$ students were asked to identify the barriers that prevented their participation in the past. The implications from this research were that educationally disadvantaged adults typically experience a combination of barriers that cause them to drop out of programs. The perceptions of barriers is impacted by age, sex, and educational level. Among groups with similar backgrounds and characteristics, differences exist in motivation and deterrence factors. Using a Deterrence to Participation scale developed for low literate populations, five deterrence factors were developed to represent the data. Factor one (Low Self-Confidence) reflected general low self esteem, specifically in regard to academic ability and fear of specific tasks required in the educational process. Factor Two (Social Disapproval) included items to determine the negative value placed on education by family or friends. Factor Three (Situational Barriers) included items such as cost, transportation, or family problems. Factor Four (Negative Attitude to Classes) measured one's dislike of school. Factor Five (Low Personal 
Priority) was indicated by items suggesting that other activities took precedence over education. The resulting typology classified six groups of low literate adults. Twelve and six-tenths of the sample had the highest mean score on Factor one (Low Self-Confidence), suggesting fear of failure, perhaps in regard to prior learning difficulties or in regard to a perception of being too old to learn. This group was characterized by a high proportion of males ( $50 \%$ compared to $32 \%$ for the sample), and a high mean age (38.2 years compared 29.7 years for the sample). Low Self Confidence was the second highest factor representing $18.9 \%$ of the sample (Hayes, 1988:7-8).

Darkenwald (1980), examined continuing education and the "hard-to-reach" adult, which included those people who have "little formal education," and "the elderly, the disadvantaged, blue-collar workers, the handicapped, the geographically isolated and many other identifiable groups and sub-groups in the general population" (Darkenwald, 1980:1). Darkenwald theorized that the most important factors characterizing the hard-to-reach adult include the following: (1) social status, consisting of low socioeconomic status based on educational attainment, occupational status, and income; (2) age, indicated by low participation in educational activities for people age 55 and older; and (3) geographic isolation due to illness or handicapping situations (Darkenwald, 1980:2-4). Darkenwald 
classified the barriers to participation for adults into

four categories: informational barriers, situational

barriers, institutional barriers, and attitudinal barriers (Darkenwald, 1980:5-6). The impact of undereducated adults is experienced throughout, however, the last barrier holds special significance for this population.

Attitudinal barriers are individually and collectively held beliefs, values, attitudes or perceptions that inhibit participation in organized learning activities. [The]... intangible barriers are for many people much more formidable than tangible ones. How individuals think about themselves, their world, and the uses of education profoundly influences their dispositions and actions regarding continuing education" (Darkenwald, $1980: 6)$.

Attitudinal barriers entail the notions that "schools are for children", or "learning is dull and difficult" (Darkenwald, 1980:6). Devaluing the educational arena as a possible positive setting, undereducated adults approach the learning environment with negative, preconceived ideas of potential benefits to be gained.

In order to further understand the characteristics of the illiterate adult, it is helpful to examine the reasons why adults choose to upgrade their basic skills and their goals. In starting over: Characteristics of adult literacy learners (1987) Smith-Burke designed a study to collect descriptive information from adults whose reading grade level scores were in the 0 to 4.9 range. In a survey taken, questions were asked to determine what makes adults decide 
to attend literacy programs. Selected from 15 program sites, $32 \mathrm{ABE}$ students were interviewed. In response to the questions "Why did you decide to attend this program? What do you hope to learn from it?", the most frequent response was job-related (16 responses), however, 10 of the 20 women in the study were the head of their households, and 22 of the total participants were unemployed. The second priority was attainment of a GED (General Equivalency Development), often desired for personal reasons, with 12 adults indicating this as a priority. The third most frequently mentioned motivational reasons (two categories mentioned each by 11 participants) were for self-improvement and because of embarrassment. Balmuth (1986), in a review of adult literacy research, generalized

employment goals (to gain or upgrade employment), hopes related to children, and a desire for self improvement are among the strongest verbalized motives in almost every study (Balmuth, 1986:11).

SELF-ESTEEM AND OTHER SPECIAL CHARACTERISTICS

Two salient features of the study population were employment status and hearing impairment. These two characteristics are examined below.

Hearing Impairment

"The study of self-concept in relation to deafness has...theoretical significance for the understanding of human development..." began a paper presented at the 88 th 
Annual Convention of the American Psychological Association in 1980 discussing deafness and self-esteem (Meadow, 1980:3). Delays in language development, coupled with difficulties in using the language system of the hearing community, poses major problems for the hearing-impaired. The author, Kathryn Meadow from Galluadet college in Washington DC, postulated that the cultural definition of a disabled person in its negative sense, carries over to the adult, with implications for self-concept and self-esteem. Meadow outlined five theoretical issues that have possible implications in the connection between self-esteem and deafness. These five issues deal with the following: 1) the development of self-concept in light of language deficiencies, 2) the influence of language in developing concepts about the self, 3) the influence of parental feelings towards the hearing-impaired child and the manifestation of those feelings in the development of the child's view of him or herself, 4) the influence of delayed abilities to build personal bonds and consequences for selfesteem, and 5) the influence of negative social and cultural views towards disabled people and the possible effects on self esteem and self concept (Meadow, 1980:4-5). Most importantly, Meadow discussed problems associated with the assessment of self-esteem using instruments developed for hearing populations. A self-esteem study of 109 subjects newly enrolled at the National Technical 
Institute for the Deaf utilized the Tennessee Self Concept Scale as an assessment instrument. The students were retested two weeks later, and the results indicated that the subjects had a "limited understanding of both the questions posed and the implications of various response choices" (Garrison, Tesch and Decaro, 1978:974). The authors concluded that "there is no evidence to indicate that deaf students can be compared accurately with hearing individuals on the variables assessed in the TSCs" (Garrison, Tesch and De Caro, 1978:973). Furthermore, an analysis of the test items indicated that $33 \%(33 / 100)$ of the items contained linguistic structures suggested as biased against hearing impaired test takers (Meadow, 1980:6).

A study designed to examine the difference in socialemotional patterns among hearing-impaired students in different educational settings, Farrugia and Austin (1980) grouped 200 subjects (ages 10-15) into four categories: 1) deaf students in public schools, 2) deaf students in residential schools, 3) hard-of-hearing students in public schools, and 4) hearing students in public schools. An inventory in research form, the Meadow/Kendall SocialEmotional Assessment Inventory for Deaf students, was used because of its appropriateness for hearing-impaired students. There were scoring procedures built into the test to eliminate questions not applicable to hearing students. 
The results indicated

...hard-of-hearing students and deaf students in public school appear to demonstrate lower levels of self-esteem than other students. Deaf students in public schools also appeared to demonstrate lower levels of social, emotional, and mature behaviors (Farrugia and Austin, 1980:535).

The authors discussed that a possible explanation for these results is related to the "social isolation and social rejection that the deaf student appears to experience in the company of hearing peers" (Farrugia and Austin, 1980:539).

\section{Employment}

In the years following the Depression of the 1930s, research documented the positive connection between selfesteem and employment status (Bakke, 1933; Pratt, 1933; Komarovsky, 1940). These studies suffered from a variety of problems including ambiguous definitions of self-esteem, methodological inconsistencies, and a lack of a theoretical base (Perfetti, Bingham, 1983; Larson, 1984). However, recent research on this issue has reported similar findings.

Larson conducted research examining the effect of unemployment on husband and wife self-esteem. Issues of marital adjustment/communication and satisfaction with family relationships were among the variables studied. Information was collected from 40 employed and 41 unemployed blue-collar couples using the Rosenberg Self-Esteem Scale. Although the unemployed group (husbands only) did report low scores on marital and family factors, this group did not 
report lower feelings of self-esteem. In identifying possible reasons for this seemingly contrary finding, Larson discussed several factors. The unemployed group was younger, recently unemployed, and had reached a higher educational level compared to the employed group. These factors might have contributed to the "positive influence on the unemployed men--giving them more self-confidence and a more optimistic attitude about future employment" (Larson, 1984:509). According to the author, the "results suggest that relatively more education coupled with youth may result in less threat to self-esteem" (Larson, 1984:509).

Another study was designed to test Super's theory hypothesizing that choice of occupation was important in seeking self-actualization. In its evaluative sense, positive self-esteem is manifested in people who have implemented self-concepts through employment (Super, 1957). Perfetti and Bingham (1983) selected male metal refinery workers. They looked at 97 employed workers, re-employed workers, and unemployed workers. Using the Rosenberg selfEsteem Scale, their results indicated that the unemployed workers scored lower in self-esteem than the other two groups. The mean rank score for the unemployed group was 18.5 while the re-employed and employed groups scored 36.5 and 52.8 respectively.

Northwest Regional Educational Laboratory (1982) reported findings from questionnaires and telephone surveys 
of 15 unemployed men and 15 unemployed women 35 years and older residing in the Pacific Northwest who had been unemployed for at least six months in order to determine how unemployment affects people in the following areas: economic effects, psychological impacts, family/sociological effects, barriers to further education, retraining and relocation to find employment. Psychological impacts were reported by ten of the respondents. These preliminary findings indicated that diminishing feelings of self-worth were expressed by one-third of the respondents (NWREL, 1982).

THEORY AND RESEARCH: SELF-ESTEEM AND ACHIEVEMENT

In general, theory and research has persistently linked self-concept and academic achievement in children (Purkey, 1970; Burns, 1979; Thomas, 1980).

For generations, wise teachers have sensed the significant and positive relationship between a student's concept of himself and his performance in school. They believed that the students who feel good about themselves and their abilities are the ones who are most likely to succeed (Purkey, $1970: 14$ ).

Purkey hesitated, however, before assuming a causal relationship between the two variables.

However, a great deal of caution is needed before one assumes that either the self concept determines scholastic performance or that scholastic performance shapes the self concept. It may be that the relationship between the two is caused by some factor yet to be determined. The best evidence now available suggests that it is a two-way street, that there is a continuous 
interaction between the self and academic achievement, and that each directly influences the other (Purkey, 1970:23).

The reciprocal relationship between the two variables indicated that change in one seems to be associated with change in the other (Marsh, 1984) and the causal relationship cannot be determined (Scheirer and Kraut, 1979) •
At the present state of knowledge it seems reasonable to assume that the relationship between self concept and academic attainment is reciprocal, not unidirectional. Academic success raises or maintains self esteem, while self esteem influences performance through expectations, standards, recognition of personal strengths, higher motivation and level of persistence. There is a continuous interplay between the benefits gained from self esteem increasing the likelihood of increased competencies and academic success, and the influence of academic success on increasing confidence, expectations and standards (Burns, 1979:283).

Thomas (1980) reflected upon the dynamics of the relationship between self-concept and achievement and theorized

...if a person considers a given school subject particularly valuable to him for his desired work, career, or leisure ambitions then failure in that subject will devalue his opinion of his ability in that area. Such failure will tend to lower his rating of his ability in other capacities and may indeed lower his whole self-esteem... It seems reasonable that a pupil's self-concept characteristics will play a role in his reactions to success and failure (Thomas, $1980: 65-66)$.

He argued for the unity of the two variables. As a set of intertwining outcomes, Thomas added 
...self-esteem is not something separate from performance but rather integral to it. It is through achievement that academic selfconfidence grows, and increased confidence in turn promotes achievement through inspiring further learning. In short, confidence and competence must increase together for either of them to flower" (Thomas, 1980:67).

Prior to the 1950s, researchers limited their inquiries regarding the explanation of academic success to factors including I.Q., social class, parental interest, ethnicity, and gender (Burns, 1979). Soon thereafter, the focus began to include personality influences, the major one being the attitudes of self-perception. Burns noted several considerations regarding the significance of the relationship connecting self-esteem and academic achievement. The first bears the most importance on this research. Burns noted

...the array of correlations linking selfconcept level and achievement, while positive and statistically significant, tends to hover in the region of 0.30 and 0.40 , a level which is not all that striking, indicating only that up to around 16 per cent of the variance in academic performance can be 'explained' in terms of self-concept level (Burns, $1979: 280)$.

Taking into account other important factors to consider in academic achievement, it is not surprising to find that self-concept alone has a moderate influence. In addressing this concern, Burns suggested that weak correlations were found due to the "frequent use of general self-concept scales which are far too wide ranging, with items nosing into a broad spectrum of areas unrelated to educational 
endeavours" (Burns, 1979:280). Burns continued to suggest that self-concept needs to be assessed in relation to particular and specific variables with questions pertaining to those specific variables.

studies have positively connected various aspects of academic achievement with facets and levels of self-concept (Wirth, 1977; Marsh, 1984; Lawrence, 1985; Hadley, 1988). However, one of the earliest, largest, and well-known studies was conducted in 1964, by Brookover and Associates. With a sample of 1,050 urban 7 th grade students in which the Self Concept of Ability Scale was used, the research team tested three hypotheses: 1) self concept of ability is positively related to academic performance, 2) self concept of ability is differentiated into specific self-concepts which correspond to specific subject areas, and 3) self concept of ability is significantly and positively related to the evaluation one perceives that others have of his/her ability. The results of this important piece of research indicated

1) There is a significant and positive correlation between self-concept and performance in the academic role; this relationship is substantial even when measured I.Q. is controlled. 2) There are specific self-concepts of ability related to specific areas of academic role performance, which differ from the general self-concept of ability. These are, in some subjects significantly better predictors of specific subject achievement than is the general selfconcept of ability. 3) Self-concept is significantly and positively correlated with the perceived evaluations that significant 
others hold of the student; however, it is the composite image rather than the images of specific others that appear to be most closely correlated with the student's selfconcept in specific subjects (Brookover, Thomas and Paterson, 1964:278).

There is a scarcity of research that examines the relationship between self-esteem and achievement in the adult population, and in the low literate adult population there is virtually none. An early study investigated nonintellectual variables and academic achievement, both relational and predictive. The subjects were from the 1967 Sophomore class at the University of Texas, Austin. The nonintellectual variables included an identity awareness scale reflecting self-development and integration, a selfconcept of ability scale comprised of items relating selfconcept of ability to academic achievement, and a selfexpectations inventory relating behaviors relevant to academic achievement. The academic achievement and aptitude variables included the grade point average and the Scholastic Aptitude Test (SAT). Using 877 subjects, the results indicated the

...measures of self-perception appeared to be positively related to scholastic achievement, although they are not equally effective predictors of achievement. Brookover's scale on the self-concept of ability as a student proved the most effective and consistent predictor, even better that the SAT (Jones, Grieneeks, 1970:203).

Davisson (1979) investigated reading deficient entering college freshman students. Davisson researched whether 
these students' self-concepts differentially affected reading gains when using different methods of instruction. Pretested for both reading (Nelson-Denny Reading Test Form A) and self-concept levels (Personal self Subscale of the TSCS), students were randomly assigned to classes teaching either content teaching of reading (through a subject area textbook) or artificial teaching of reading (through commercially prepared reading study skills books). The findings of the semester-long study suggested that students' self-concepts did not differentially affect reading gains in the two different methods of instruction. Students in both groups made comparable gains in reading (Davisson, 1979).

Curtis (1982) studied community college readers' perceptions of themselves as readers and the relationship of those perceptions to reading ability. The study also examined the effects that process-oriented reading instruction had upon those perceptions. Reading placement scores and an attitude survey regarding the reading process and reading self-concept were implemented. T-test scores $(p<.05)$ of the 15 subjects enrolled in a "Reading Efficiency" class showed significant improvement in students' attitudes about themselves as readers and in their attitudes regarding the reading process. Interviews conducted revealed an important theme concerning the internalization of the image of a competent reader. Subjects' interviews revealed 
....instruction and attitude of the classroom teacher are instrumental in fostering better self-concepts and in changing attitudes about the nature of the reading process (Curtis, 1982:6).

A report of research-in-progress focusing on "the effectiveness of a whole language oriented literacy program in furthering the reading and writing abilities of adult learners in ABE programs" (Patton, Roskos, in press) is examining the lasting effects of the literacy programs on students' achievement and self-perceptions six months after becoming involved with the literacy program. Using standardized instruments to measure cognition and the TSCS to measure the affective area, preliminary findings are indicating

...students' self-concepts/self-esteem are consistently low upon entry into the $A B E$ sites; however, improvement tends to occur as the length of the students' participation increases (Patton, Roskos, in press).

In summary, documented interactions between self-esteem and achievement in children coupled with initial research regarding adult readers indicates that additional information on adults is an important next step. Theory and research suggests that the relationship between the variables is consistent in predicting academic success in children. Expanding upon the information to date, speculations can be made that the relationship between selfesteem and achievement is also notable in the low literate adult population. Considering the characteristics of 
undereducated adults, and noting the increasing problem of adult illiteracy, the relationship between self-esteem and achievement in this population deserves attention. 


\title{
CHAPTER III
}

\author{
METHODOLOGY
}

\section{RESEARCH QUESTION}

The purpose of this study is to investigate the relationship between self-esteem and reading comprehension in the low literate adult population.

\section{HYPOTHESIS}

The hypothesis is presented in three sections. First, it is hypothesized that the study population will show an increase in reading comprehension over the course of study. Second, the subjects will show an increase in self-esteem over the course of study. Lastly, it is hypothesized that there is a positive correlation between the increase in self-esteem and the increase in reading comprehension in low level reading adults over the course of the study.

$$
\text { STUDY DESIGN, STUDY SETTING, AND SUBJECTS }
$$

This study was a one group design format. The study was descriptive and correlational in nature and took place at the Southeast center of Portland Community college. Portland Community college is a large, multi-campus 
community college that serves urban, suburban and rural populations. The college offers a broad base of credit and non-credit courses and covers 15,000 square miles. The college-wide average student age for the school year 19881989 was 35.7 (S. Bach, personal communication, May, 1990). As a non-credit course, 431 students were served in the Adult Basic Education program throughout the entire college system in the 1989 Fall term (J. Ponce, personal communication, June 29, 1990.)

The 21 student sample for this study was taken from an Adult Basic Education class held at the Southeast center of Portland Community college. Adults attend the open entry/open exit class in order to upgrade their basic skills. The class met five days a week for three hours a day, from 9:00 a.m. to 12:00 p.m. Each term runs eleven weeks. Approximately $30 \%$ of class time was spent on reading instruction, divided between individualized and teacherdirected instruction. Reading practice also occurred throughout the program in the instruction of other subjects such as writing, spelling, grammar, and math. Minimum attendance requirements for study participation was $45 \%$. The 21 students in the sample ranged in age from 20 to 60 . Students' initial reading levels fell in the 0 to fifth grade range.

Class time was divided between individualized learning and group instruction. Students were initially assessed and 
placed in materials and small instructional groups appropriate to their skill level. The class was staffed with two teachers and at least two volunteer tutors each day. Reading instruction occurred in small groups (five to eight students) with an instructor. This instruction included oral reading and discussion. Critical reading skills, problem solving and interpretation were stressed. students continued their seatwork individually or with other students. Mathematics, writing, and spelling were individualized, although students were encouraged to work together. Language and vocabulary were taught to the entire class. Science, geography and a newspaper discussion group were optional learning sections for the students. Films on a variety of topics and captioned for the hearing-impaired, were shown once a week. Speakers from the community came every two weeks to speak to the class on topics including health care, nutrition, employment opportunities, and the community library services. Once a week an instructor read aloud to the class from a book written by an oregon author. At the end of the term, the author visited the class to share his experiences as a writer.

An independently conducted self-reported student Profile (see Appendix A) completed during the course of study indicated that $39 \%$ of the students had been in the program up to two terms. Thirty-six percent of the students reported attending the class between two terms and one year. 
Twenty-five percent of the students indicated that they had come to the $A B E$ class for two or more years. While attending public school, $32 \%$ of the students reported attending a special education program. In addition, $69 \%$ indicated that they have a type of disability including physical disabilities (hearing or speech-impairment, epilepsy), mental illness, job related injuries, or developmental disabilities. A majority of the students reported receiving assistance (Social security Insurance, disability compensation, or worker's compensation).

\section{INSTRUMENTATION}

Two instruments were selected; one to assess selfesteem and one to assess reading comprehension. A self-made demographic survey was devised to collect descriptive information. The Counseling form of the Tennessee self Concept Scale (TSCS) measured self-esteem and was selected as it is a self-esteem measure intended for individuals "aged 12 or older who can read at approximately a fourthgrade level or higher" (Roid, Fitts, 1988:1). Additionally, the test can be administered orally. The Piers Harris and Rosenberg Self Esteem Scale were reviewed for use in the study. The Piers Harris was designed for use with children and therefore not appropriate for the study population. The Rosenberg Self Esteem Scale, although a short ten item assessment, was reviewed and judged to be too vague and 
difficult to understand. Additionally, it was determined that the short length of the instrument might cause internal validity problems.

The comprehension section of the Brigance Comprehensive Inventory of Basic Skills measured reading comprehension in half year increments after primer level, from lower first grade to upper third and in full year increments from fourth through ninth grade. This measure is currently used to assess grade level reading abilities in the study setting. Although designed for use with children, the instrument was selected because it provides grade level indications in a non-threatening manner. The graded paragraphs are short; the print is large, and test-taking time is minimal.

\section{Tennessee Self Concept Scale}

This instrument was developed to study and understand human behavior (Fitts, W. H., 1964). The scale consists of 100 self-descriptive items rated on a five-point rating scale (see Appendix B). It is self-administering with individuals or groups and can be given orally. The Tscs can be used with subjects age 12 and up with a minimum reading level of fourth grade. There is no time limit for completion. The counseling form was designed for use by counselors in academic settings and community agencies and can be used for self-interpretation. The scale contains two subscales. The self Criticism scale includes 10 items that are mildly derogatory and seeks to test for validity and 
candidness. Most people can admit that these items are true for themselves. Denial of most of these statements indicates defensiveness; the test taker might be attempting to create a favorable image of him or herself or refusing to admit to common weaknesses. Low scores point to an indication that the subject has not been honest. The remaining 90 items comprise the Total Positive Subscale. They are equally divided between positive and negative items. Other sub categories of the scale (row and column scores) provide measures of identity, self satisfaction, behavior, physical self, moral-ethical self, personal self, family self, and social self. Two other scores are calculated. The Variability score indicates the consistency of self-perception across the sub categories, with high scores suggesting high variability, reflecting little unity in self-perceptions. The Distribution score is a reflection of how the subject distributes his/her responses across the five-point scale. Low scores indicate frequent responses in the middle range, while high scores are characteristic of frequent extreme responses. The TSCS provides an overall profile of self-esteem, with high Total Positive scores and low Variability scores indicating general feelings of selfworth, personal value, and self-confidence. Low Total Positive scores and high Variability scores indicate doubts concerning self-worth, and a lack of confidence (Burns, 1979; Mitchell, 1985; Roid, Fitts, 1988). 
The group from which the norms were developed was from a sample of 626 persons, age 12-68. Equal numbers of both male and female subjects were represented as well as a broad range of socio-economic and ethnic groupings. The testretest coefficients of all major scores are given (see Appendix C). Other evidence of reliability is found in the similarity of profile patterns found through repeated measures of the same individuals over long periods of time and through various types of profile analysis. The authors have demonstrated that the distinctive features of the individual reliability coefficients are still present for most persons a year or more later (Roid, Fitts, 1988). Reliability coefficients for the various profile categories used in computing the NDS (Number of Deviant Signs score) fall mostly in the .80 to .90 range (Roid, Fitts, 1988). Validation procedures cover both content validity and construct validity (correlation with other personality measures). Content validity is demonstrated by a classification system which is used for row and column scores. This system is dependable, as each item was retained only by unanimous agreement by judges that it was classified correctly (Roid, Fitts, 1988:87-88). Most of the TSCS scores correlate with other personality measures, such as, the MMPI (Minnesota Multiphasic Personality Inventory), the Edwards Personal Preference Schedule, and the Inventory of Feelings (Roid, Fitts, 1988:70-76). 
The TSCS can be orally administered or selfadministered with either groups or individuals. The answer sheet is arranged so that the subject responds to every other item. Clear instructions are necessary to avoid confusion. Minimal training of test administrators is necessary.

A number of concerns regarding the TSCS have been noted (Bentler, Suinn, 1972) which relate to problems with the manual. Some of the concerns related to the absence of information concerning the internal structure of the test, the interpretation of the data base, test validation, and test interpretation. Scoring methods are extensive and tedious although well organized in the test packet. The TSCS, in summary, is one of the better measures combining group discrimination with self-concept information (Buros, 1972 ) •

Brigance Comprehensive Inventory of Basic Skills

The Brigance is a criterion referenced specificobjective test (Brigance, A. H., 1983) that covers a range of skill areas for levels pre-kindergarten to ninth grade (see Appendix D). The comprehension section of the Brigance consists of short, graded paragraphs based on a Fry Readability, which indicates reading level by grade level.. Forms $A$ and $B$ are available for split-half reliability. The test is teacher-administered for reading levels primer to upper first grade. For each of these levels, the student 
reads a passage and then answers oral questions. For the remaining levels, lower second to ninth, the Brigance is self-administering. The student reads the passage which is followed by multiple choice comprehension questions. Students circle the letter of the correct response. There are three possible answer choices for levels lower second through upper second grade. For the remaining levels, lower third through ninth, there are four answer choices. Four out of five correct answers ( $80 \%$ ) are necessary for mastery. Time limits are based on teacher discretion. Reading ability is assessed in half year increments after the primer level, from lower first to upper third grade, and in full year increments from fourth through ninth grade (Mitchell, 1985).

There are no reliability or validity data available. However, when both Forms $A$ and $B$ are used (a total of ten comprehension questions) face validity is quite high. As a currently used assessment tool to indicate grade level abilities, the Brigance is successful in providing the information accurately, quickly, and with little embarrassment to the test-taker. Seven out of ten correct responses (cumulative total) on Forms $A$ and $B$ were required for placement at a given grade level.

The major concerns of this instrument (Mills, Swerdlik, 1985) surround the lack of appropriate information on item quality, content and construct validity, and alternative 
form reliability. These issues limit the generalizability of the test results. The reviewers agree that the test appears to yield useful information which is easily utilized for individual assessment in educational programs. It is recommended that the test be used in conjunction with a norm-referenced test. The testing kit refers to an assessment of content validity; however, results of this assessment are not presented. No mention is made of construct validity. The test author, A. Brigance indicated that test paragraphs were chosen through a review of the most recently published tests of several commonly used basal readers (Mills, Swerdlik, 1985).

\section{Demographic survey}

A Demographic Survey was constructed to further describe the study population (see Appendix E). Information collected yielded the following information: gender, highest grade achieved in school, parent's educational level, employment status, and type of employment.

\section{DATA COLLECTION}

The TSCS was pilot tested during the 1989 Summer session with six students in the same class in which the study was conducted. It was noted that the answer sheet was confusing to follow, and some of the vocabulary was difficult to understand. 
In the Fall of 1989, the comprehension section of the Brigance Comprehensive Inventory of Basic Skills was given to the students as they entered the $A B E$ class at the beginning of the term. The instructions to the students were to read each paragraph and then answer the multiple choice questions following each paragraph by circling the letter of the correct answer. Students who were unable to read the initial paragraph at lower second grade level were given the test orally. These subjects were asked to read paragraphs beginning at a primer level and then answer oral questions. Testing stopped when subjects missed more than $70 \%$ of the questions. Subjects completed both paragraphs for each level (form $A$ and $B$ ). The reading assessment was untimed. Administration continued throughout the first two weeks of the term, however, all but three students took the test within the first week of the term. Assessing reading level is standard procedure for placement of students in instructional materials in the $\mathrm{ABE}$ program.

on the Friday of the first week of the term, the research project was discussed with students. The Informed Consent forms (see Appendix F) were passed out and were reviewed thoroughly. Questions were answered, and the forms were signed by the students. A demographic questionnaire was also completed at this time (see Appendix E). One-half of the TSCS was administered orally on this day. Make-ups were given on the following Monday and individually skipped 
items were answered throughout the second week. The second half was given at the end of the second week. The first half of the test took one hour to administer, and the second half took 45 minutes. The students were given paper markers to use to help them keep their place as subjects respond to every other item on the answer form. The five-point scale is printed on the cover of the test booklet. All students had a printed copy of the description of the scale in front of them so they could refer to it as needed. A few of the students chose to follow the printed test booklet, however, most concentrated on the oral reading of the instrument. The hearing-impaired students followed the same testing procedures with the exception that an interpreter signed the test items for the students. The normal course of instruction proceeded throughout the 11 week term. The subjects were posttested using the same assessment instruments and test administration procedures the tenth and eleventh week of the term.

\section{DATA ANALYSIS}

Data analysis was completed using statistical Package for the Social Sciences (SPSS). T-tests were conducted on pre- and posttest scores for both the comprehension section the Brigance Comprehensive Inventory of Basic Skills and the Tennessee Self Concept Scale. The Pearson Correlation Coefficient assessed the correlation between the gain in 
reading and change in self-esteem and also was utilized to control for the effects of the demographic variables. The analyses were performed using a .05 level of significance.

\section{LIMITATIONS}

Important study limitations deserve attention. They include the following issues: 1) the Tennessee Self concept Scale including test administration, the self-report nature of the test and the stability of self-esteem, 2) the Brigance Comprehensive Inventory of Basic Skills and the lack of critical norming information, and 3) design concerns including the length of the study, sample size and the influence of unrelated stress factors.

\section{Tennessee Self Concept Scale}

Test administration. There were a variety of concerns related to the administration of the instrument. The nonsequential ordering of the test items (respondents answer every other item) was initially a problem, even though subjects used markers as a guide. As the test proceeded, the marking system became clearer. The phrasing of some test items was confusing, especially statements posed in the negative. For example, Item number 7 reads "I am neither too fat nor too thin." Item number 59 reads "My friends have no confidence in me." These statements were difficult because the subjects were unclear as to exactly what the statement 
meant. Other test statements contained sophisticated vocabulary or concepts, such as Item number 25, "I am satisfied with my moral behavior." Additionally, subjects appeared to have difficulty in distinguishing between shades of truth or falseness. For example, the scale discriminations ("completely false, mostly false, partly true and partly false, mostly true and completely true") were conceptually difficult for some students (see Table II for extreme ranges on Distribution scores).

Self-reporting test information. Wylie (1961) discussed the methodological problems inherent in selfconcept research. The self-report nature of self-concept instruments is an important consideration.

We would like to assume that subject's self-report responses are determined by his phenomenal field. However, we know that it would be naive to take this for granted, since it is obvious that such responses may also be influenced by (a) subject's intent to select what he wished to reveal to the examiner; subject's intent to say that he has attitudes or perceptions which he does not have; (c) subject's response habits, particularly those involving introspection and the use of language;

(d) a host of situational and methodological factors which may not only induce variations in (a), (b) and (c), but may exert other more superficial influences on the responses obtained (Wylie, 1961:24).

Purkey (1970) and Burns (1979) discussed the two methods of collecting information regarding self concept: observation and self-report. Of the latter, Burns noted 
that self-reporting self-concept information makes available "what a person is willing to reveal about himself" (Burns, 1979:74). This reflects on the differentiation between the self-concept and the self-report of the self-concept. The accurateness of the information depends upon

(a) the clarity of the individual's awareness; (b) the availability of adequate symbols for expression; (c) the willingness of the individual to cooperate; (d) social expectancy; (e) the individual's feeling of personal adequacy; (f) his feelings of freedom from threat" (Burns, 1979:75).

Purkey concluded his discussion of the problems of selfreport evaluations with

there are a host of contaminating variables in self-reports...this means that conclusions about self-concept based solely on self-reports must be taken with a great deal of salt. However, in spite of their weaknesses and limitations, self-reports do reveal characteristics of the self... (Purkey, $1970: 60-61$ ).

Acknowledging and considering the limitations while supporting the positive nature of self-report, Burns indicated that "Self-report techniques are literally the only method available for measuring the self concept, and if they are to be rejected then psychology would be seriously limited" (Burns, 1979:77).

stability of self-esteem. The second issue of concern regarding self-esteem is the stability or consistency of the construct and how often one can expect to detect changes. The TSCS manual reports that the test-retest reliability 
change scores are quite small for a median time period of six weeks (Roid, Fitts, 1988:66). Purkey (1970) discussed self-image shifts and stated that the perception of self is "ultraconservative" and "resists change and strives for consistency" (Purkey, 1970:11). In support of the organization and consistency provided by the self, change is resisted as much as possible. Purkey added, however, that "the self will change if conditions are favorable" (Purkey, 1970:12). The TSCS manual also states "It is logical to expect that certain life experiences would affect the way in which a person sees himself or herself" (Roid, Fitts, 1988:81). However, changes are reflected in predictable ways (Roid, Fitts, 1988).

Pendergast and Binder (1975) reported the testing of the relationships of selected self-concept and academic achievement measures. Using the Pearson product-moment correlation coefficient, they found that of the three instruments reviewed, the Tennessee Self-Concept Scale, the Brookover Self-Concept of Ability Scale, and the Rosenberg Self-Esteem Scale, the TSCS showed the highest correlation with reading $(.984$ with $\mathrm{p}<.001)$ (Pendergast and Binder, $1975: 94)$.

Brigance Comprehensive Inventory of Basic Skills

The lack of reliability and validity information for the instrument presented an important concern. The choice of this test was made due to the ease of administration and 
appropriateness to the population under study. The Brigance gives grade level indications in a non-threatening manner. The passages are short and test taking time is minimized. Even though the Brigance is used in $A B E$ classes to assess comprehension for placement in instructional materials, the test was designed for use with children.

\section{Design concerns}

Length of the study. The question regarding the detection of change in either of the two variables within the given time frame is important to note. The term ran for eleven weeks. Testing of both variables took place the first two weeks and the last two weeks in order to obtain complete information on all subjects. The actual time to demonstrate change was seven weeks.

Sample size. The original design of the study was to include a minimum of 30 subjects with the inclusion of as many as possible. "For correlational studies at least 30 subjects are needed to establish the existence or nonexistence of a relationship" (Gay, 1987:115). However, the open entry/open exit nature of the program, coupled with the attendance minimum set at $45 \%$, limited the participation of subjects to 21 .

Unrelated stress factors. General life events of significance could have confounded the results of the study. None of the subjects underwent major life changes (employment changes, major illness, marriage, divorce, 
family death) during the course of study. However, it must be noted that all confounding influences brought about by stress factors were not controlled within the limits of the study. 
CHAPTER IV

\section{RESULTS}

The results of the demographic survey are presented in Table I. Ten students reported 12 or more years of education, and one student reported two years of college in a foreign country. However, the mean of the highest grade completed for the five foreign born subjects was 10.6 , while the mean for the sixteen U.S. born subjects was 9.4 years. of the five hearing-impaired students, three were significantly impaired and use sign language to communicate. The remaining two students were hard-of-hearing and obtained hearing aids after the course of the study. In the significantly hearing-impaired subjects, two of the three attended special schools for the deaf, while the remaining one attended a public school. The mean of highest grade completed for the three significantly hearing-impaired was 11.33, while the mean for the two hard-of-hearing was sixth grade. It should be noted that one of the hard-of-hearing subjects had no schooling, and the other completed 12 th grade.

An additional piece of information collected was education of the subjects' parents. Father's education was unknown for $15(71.4 \%)$ of the sample. For the remaining six 
students, the average education of the fathers was nine years. Four of the six fathers completed 12 or more years of education. Mother's education was unknown for 14 (66.7\%) of the sample. For the remaining third of the mothers, average education was ten years. Four of the seven mothers completed 12 or more years of education.

\section{TABLE I}

RESULTS OF DEMOGRAPHIC SURVEY

\begin{tabular}{|c|c|c|c|c|c|}
\hline \multicolumn{2}{|c|}{ Demographic Factors } & Number & Percent & \multicolumn{2}{|c|}{ Mean } \\
\hline \multicolumn{2}{|l|}{ Age } & $\begin{array}{c}20-60 \text { yrs. } \\
\text { (range) }\end{array}$ & - & \multicolumn{2}{|c|}{38 yrs. } \\
\hline \multirow{2}{*}{ Gender } & Female & 9 & 42.9 & \multicolumn{2}{|c|}{-} \\
\hline & Male & 12 & 57.1 & \multicolumn{2}{|c|}{-} \\
\hline \multirow{2}{*}{$\begin{array}{l}\text { Highest } \\
\text { Grade } \\
\text { Completed }\end{array}$} & $0-8$ & 6 & 28.6 & 5 & \multirow{2}{*}{9.7} \\
\hline & $9-14$ & 15 & 71.4 & 11.6 & \\
\hline \multirow{4}{*}{ Employment } & Unemployed & 15 & 71.4 & \multicolumn{2}{|c|}{ - } \\
\hline & Employed & 6 & 28.6 & \multicolumn{2}{|c|}{ - } \\
\hline & Part-time & 4 & 66.7 & \multicolumn{2}{|c|}{-} \\
\hline & Full-time & 2 & 33.3 & \multicolumn{2}{|c|}{ - } \\
\hline \multirow{2}{*}{$\begin{array}{l}\text { Hearing } \\
\text { Status }\end{array}$} & Hearing & 16 & 76.2 & \multicolumn{2}{|c|}{-} \\
\hline & Hearing-Impaired & 5 & 23.8 & \multicolumn{2}{|c|}{-} \\
\hline \multirow{2}{*}{$\begin{array}{l}\text { Origin } \\
\text { of } \\
\text { Birth }\end{array}$} & U.S. Born & 16 & 76.2 & \multicolumn{2}{|c|}{ - } \\
\hline & Foreign Born & 5 & 23.8 & \multicolumn{2}{|c|}{ - } \\
\hline
\end{tabular}


Employment status was ascertained for the sample. Jobs for the six students who reported part or full time work included housekeeper, volunteer, tavern security guard (bouncer), lawn mower, telephone solicitor, and dishwasher.

Findings of the pre- and posttest scores for the Tennessee Self Concept Scale are presented in Table II. The mean Total Positive scores changed between pre- and posttests by a value of 10.6 (mean of 319.7 for the pretest and 330.3 for the posttest). This change was significant at the 0.039 level. The lower end of the range of the Total Positive scores changed from 253 (pretest) to 266 (posttest) while the upper end of the range changed from 357 (pretest) to 415 (posttest).

The mean t-test scores for Self Criticism decreased by a 0.9 , from a 33.0 (pretest) to a 32.1 (posttest). This change is not significant $(p=.191)$. The mean variability scores decreased by 6.1 , from 53.8 (pretest) to 47.7 (posttest). The downward direction of the Variability score is expected if self-esteem improves, and the degree of change is significant at the .015 level. The mean scores for Distribution decreased by 3 , from 128.4 (pretest) to 125.4 (posttest). This change is not significant ( $p=$ $.275)$. 


\begin{tabular}{|c|c|c|c|c|c|}
\hline \multirow{3}{*}{ 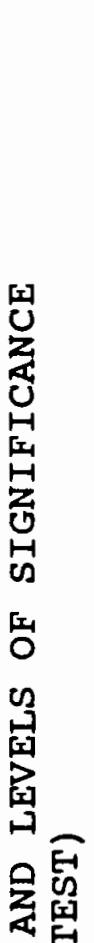 } & \multirow{2}{*}{ 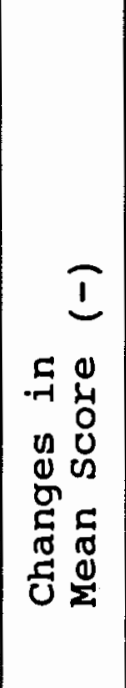 } & $\begin{array}{l}a \\
m \\
0\end{array}$ & $\begin{array}{c}{ }^{-1} \\
\sigma \\
-1\end{array}$ & $\begin{array}{l}n \\
-1 \\
0\end{array}$ & $\stackrel{n}{\sim}$ \\
\hline & & $\begin{array}{c}0 \\
\dot{0} \\
-1\end{array}$ & $\begin{array}{l}\hat{a} \\
\dot{0}\end{array}$ & $\begin{array}{l}\tilde{1} \\
\dot{0}\end{array}$ & $\begin{array}{l}0 \\
\dot{0}\end{array}$ \\
\hline & 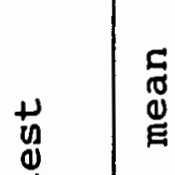 & $\begin{array}{l}m \\
\dot{m} \\
m\end{array}$ & $\begin{array}{r}\vec{N} \\
\dot{m}\end{array}$ & $\stackrel{r}{\check{\sigma}}$ & $\begin{array}{l}n \\
n \\
n \\
r\end{array}$ \\
\hline 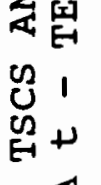 & $\begin{array}{l}+ \\
+ \\
0 \\
0 \\
0\end{array}$ & $\begin{array}{ll}1 & n \\
0 & \sim \\
0 & \sim \\
N & \end{array}$ & \begin{tabular}{l}
$\infty$ \\
\multirow{j}{1}{} \\
$\dot{0}$ \\
$\stackrel{N}{ }$
\end{tabular} & $\begin{array}{l}n \\
\infty \\
1 \\
\sim \\
N\end{array}$ & $\begin{array}{l}0 \\
9 \\
-1 \\
1 \\
\infty \\
n\end{array}$ \\
\hline 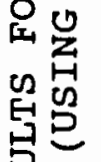 & 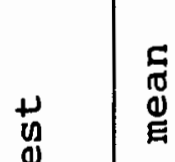 & $\begin{array}{l}r \\
\dot{a} \\
\dot{m}\end{array}$ & $\begin{array}{l}0 \\
\dot{m}\end{array}$ & $\begin{array}{l}\infty \\
\dot{m} \\
\text { in }\end{array}$ & $\begin{array}{l}+ \\
\infty \\
N \\
\sim\end{array}$ \\
\hline 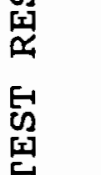 & $\stackrel{u}{u}$ & ${ }_{n}^{n} \stackrel{n}{n}$ & $\begin{array}{l}a \\
+ \\
1 \\
0 \\
0\end{array}$ & 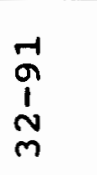 & $\begin{array}{l}n \\
\infty \\
+1 \\
1 \\
1 \\
\infty\end{array}$ \\
\hline $\begin{array}{l}\tilde{U}^{2} \\
0 \\
0 \\
0 \\
\end{array}$ & 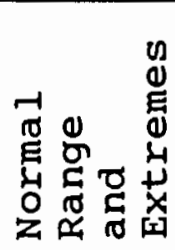 & 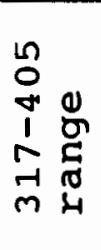 & 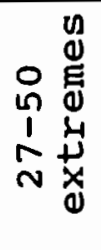 & 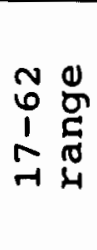 & 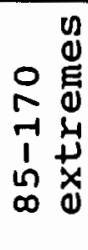 \\
\hline a & & 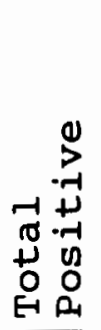 & 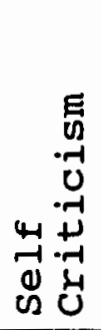 & 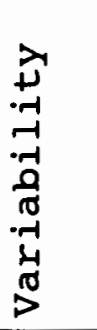 & 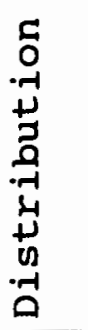 \\
\hline
\end{tabular}


An increase in positive self-esteem using the TSCS is reflected in a correlation between increasing Total Positive scores with decreasing Variability scores (Roid, Fitts, 1988:17). Table III presents the correlation coefficient and $\mathrm{P}$ value for the change in Total positive and change in Variability scores from pre- and posttests for the study population. The correlation is not statistically significant $(p=.303)$.

\section{TABLE III}

CORRELATION IN MEAN SCORES BETWEEN CHANGE IN TOTAL POSITIVE AND CHANGE IN VARIABILITY (USING PEARSON CORRELATION COEFFICIENT AT .05 LEVEL OF SIGNIFICANCE, DF=19)

\begin{tabular}{|l|c|c|}
\cline { 2 - 3 } \multicolumn{1}{c|}{} & \multicolumn{2}{c|}{ Total Positive } \\
\cline { 2 - 3 } \multicolumn{1}{c|}{} & c.c. & Level of Significance \\
\hline Variability & .1192 & .303 \\
\hline
\end{tabular}

Findings of the pre- and posttest scores for the Brigance Comprehensive Inventory of Basic Skills are presented in Table IV. The mean change between pre- and posttest increased a half grade level from upper second grade to lower third grade. This was significant at the .002 level using a two-tailed t-test.

Table $V$ presents the results of the Pearson Correlation coefficient on change in reading (Brigance) and self-esteem 
(TSCS) scores. None of the values demonstrated a significant covarying relationship.

An analysis of the demographic factors in association with change in self-esteem and reading levels was conducted. Findings are presented in Table VI. None of the demographic variables were significantly correlated with change in reading. The only demographic variable demonstrating a correlation with a change in Total Positive scores were work status $(p=.020)$ and hearing status $(p=.011)$. The mean change in Total Positive scores for employed subjects was 28.8, while the mean change in Total Positive scores for unemployed subjects was 5.1. The mean change in Total Positive scores for the hearing subject was 19.9 , while the mean change for the hearing-impaired subject was -.12 .0 .

\section{TABLE IV}

PRE- AND POSTTEST RESULTS FOR BRIGANCE COMPREHENSIVE INVENTORY OF BASIC SKILLS

\begin{tabular}{|c|c|c|c|c|c|}
\hline & \multicolumn{2}{|c|}{ Pretest } & \multicolumn{2}{|c|}{ Posttest } & \multirow{2}{*}{$\begin{array}{l}\text { Level of } \\
\text { Significance }\end{array}$} \\
\hline & range & mean & range & mean & \\
\hline $\begin{array}{l}\text { Reading } \\
\text { Scores }\end{array}$ & $0-5$ & $\begin{array}{l}\text { upper } \\
\text { second }\end{array}$ & $0-9$ & $\begin{array}{l}\text { lower } \\
\text { third }\end{array}$ & .002 \\
\hline
\end{tabular}


TABLE V

CORRELATION IN MEAN SCORES BETWEEN CHANGE IN TSCS AND CHANGE IN BRIGANCE COMPREHENSIVE INVENTORY OF BASIC SKILLS (USING PEARSON CORRELATION COEFFICIENT AT .05 LEVEL OF SIGNIFICANCE, $D F=19$ )

\begin{tabular}{|c|c|c|}
\hline \multirow{2}{*}{$\begin{array}{l}\text { TSCS Test } \\
\text { Components }\end{array}$} & \multicolumn{2}{|c|}{ Brigance } \\
\hline & Correlation coefficient & P Value \\
\hline Total Positive & .0594 & .399 \\
\hline Self Criticism & -.1608 & .243 \\
\hline Variability & .1414 & .271 \\
\hline Distribution & -.1049 & .326 \\
\hline
\end{tabular}


TABLE VI

DEMOGRAPHIC CORRELATIONS WITH CHANGE IN TOTAL POSITIVE SCORES AND READING LEVEL (USING PEARSON CORRELATION COEFFICIENT AT .05 LEVEL OF SIGNIFICANCE, DF = 19)

\begin{tabular}{|l|c|c|c|c|}
\hline \multirow{2}{*}{$\begin{array}{l}\text { Demographic } \\
\text { Variables }\end{array}$} & \multicolumn{2}{|l|}{$\begin{array}{l}\text { Change in Total } \\
\text { Positive Score }\end{array}$} & \multicolumn{2}{l|}{ Change in Reading } \\
\cline { 2 - 5 } & Corr. Coef. & P Value & Corr. Coef. & P Value \\
\hline Attendance & .1424 & .269 & .3232 & .076 \\
\hline Age & .0446 & .424 & .0872 & .356 \\
\hline $\begin{array}{l}\text { Highest Grade } \\
\text { Completed }\end{array}$ & -.1352 & .280 & -.0100 & .483 \\
\hline $\begin{array}{l}\text { Work Status } \\
\text { Hearing } \\
\text { Status }\end{array}$ & .4510 & .020 & -.229 & .159 \\
\hline $\begin{array}{l}\text { Origin of } \\
\text { Birth }\end{array}$ & .3454 & .063 & .1620 & .241 \\
\hline \begin{tabular}{l} 
Gender \\
\hline
\end{tabular} & .0323 & .445 & -.0697 & .382 \\
\hline
\end{tabular}




\section{CHAPTER V}

\section{DISCUSSION}

\section{INTERPRETATION}

Eleven out of 21 subjects ( $54 \%$ ) completed 12 th grade and, therefore, went through a formal educational system to completion. However, the average reading grade level for these subjects was pretested at upper second grade. It appears that these subjects were passed out of high school without mastering twelfth grade competencies. Of those 11, three subjects are foreign born and completed high school in their native country. This may indicate that low reading levels, unequal to their highest grade completed, reflect that English is their non-native language. Nevertheless, eight out of sixteen ( $50 \%$ ) of the U.S. born subjects with low reading scores completed twelve years of formal education in this country. According to subjects' selfreport, $32 \%$ of the subjects reported attending a special education program while in public school.

The mean age of the sample population was 38.5 years. For the school year 1988-89, this compares to 35.7 years of age for the total Portland Community college system. In addition, this compares to a mean age of 30.2 years for College-wide, non-credit Adult Education sections, which 
includes Adult Basic Education, General Education Development, and English as a Second Language (S. Bach, personal communication, June 12,1990$)$. The mean age for the study population was older than the mean age for both the college in general and for the Adult Education portion of the total college population.

Eight of the subjects' parents (within five families) completed 12 or more years of school. Four of these subjects themselves also completed an average of 12 years of education. The one exception was the subject who did not attend school at all, as the parents considered the subject, as a child, uneducable. It appears that in this study, parents who completed school are more likely to have children who also completed school. However, parent educational levels were unknown for $71.4 \%$ of the fathers and $66.7 \%$ of the mothers.

Less than one-third of the subjects were employed full or part time. The jobs they held were generally low wage earning positions. This might reflect the link between literacy levels and wage earning power.

The Total Positive score in relation to the variability score gives a general pattern of self-esteem levels. "In other words, the profile pattern of the typical positive self-concept shows low Variability and high Positive scores" (Roid, Fitts, 1988). It appears that using the TSCS there was no demonstrated change in self-esteem during the study 
period (Table III). Some possible reasons for this lack of demonstrated change include test administration difficulties, self-report considerations, and stability of self-esteem over time.

The normal range for Total Positive scores on the TSCS is 317 to 405 (Roid, Fitts, 1988). The mean Total Positive scores for the study population on the pre and posttests were low-normal (319.7 for the pretest and 330.3 for the posttest). This falls into the 18th to 28 th percentile, respectively. However, significant gains were observed through the course of the study (Table II).

As a determinant of validity, self criticism scores indicate candidness and honesty. The means for self Criticism scores remained virtually unchanged between preand posttest (Table II). The extremes for self criticism scores on the TSCS are 27, very low, to 50, very high (Roid, Fitts, 1988). The mean Self Criticism pre- and posttest scores for the study population were in the 40 th and 35 th percentile, respectively. These scores indicate overall validity in this sub-scale. Two subjects (9.5\%) scored below the low extreme on the pretest, and four subjects (19.9\%) scored below the low extreme on the posttest. This gives an indication that further investigation might be necessary to insure candidness (Roid, Fitts, 1988).

The Variability score indicates the consistency of self-perception across the sub categories. High scores can 
be interpreted as high variability or a lack of unity in self-perceptions. The mean pre-test score for Variability (53.8) was at the high end of the range. Mean posttest scores (47.7) demonstrated a significant decrease indicating more consistency in students' responses.

The Distribution scores are a reflection of how the subject distributes his/her responses across the five-point scale. Low scores indicate frequent responses in the middle range, while high scores are characteristic of frequent extreme responses. The means for Distribution scores changed only slightly between pre- and posttest (Table II). The extremes for Distribution scores on the TSCS are 85, very low, to 170 , very high (Roid, Fitts, 1988). The mean Distribution pre- and posttest scores were in the 61st and 57 th percentile, respectively. Seven subjects (33.3\%) scored either above or below extreme scores on both the preand posttests. The TSCS manual states that subjects falling above or below the extremes are "showing indecision or extreme guardedness... A true picture of self-concept is very difficult to obtain from such a test-taking approach" (Roid, Fitts, 1988:16). As the test examiner, my observation was that subjects found it difficult to distinguish between shades of truth or falseness when responding to the test items. Examination of the test sheets confirmed this observation. My judgement is that subjects, unable to make the distinction between the test scale indications, fell 
into a more comfortable pattern of marking extreme degrees of complete truth or complete falseness or marking consistently in the middle range.

The Brigance measured reading comprehension in half year increments from lower first to upper third grade, and in full year increments from fourth though ninth grade. Mean increases in reading level were reflected in an overall grade gain of one-half year through the course of the study (Table IV). This indicates that reading comprehension improved significantly through the course of the study.

There was no significant correlation between change in self-esteem and change in reading levels (Table V). When comparing the scores with demographic characteristics, an association was noted between work status and change in Total Positive scores as well as hearing status and change in Total Positive scores. Those who were employed had higher Total positive scores, and the hearing subjects had higher Total Positive scores. Although this is interesting, the same correlation did not hold true for employment and hearing status when compared with general increase in selfesteem as measured by the combination of Total Positive and Variability scores.

\section{CONCLUSIONS AND RECOMMENDATIONS}

In summary, there were three hypotheses tested in this study. The conclusions of each are presented below: 
1) The study population will show an increase in reading comprehension over the course of the study.

Results of the Comprehension section of the Brigance Comprehensive Inventory of Basic Skills demonstrated a significant rise in reading levels for the study population over the course of the investigation.

2) The study population will show an increase in selfesteem over the course of the study.

Results of the Tennessee Self Concept Scale demonstrated a significant rise in the Total Positive scores and the Variability scores. However, the strongest indication of self-esteem is reflected in increasing Total Positive scores and decreasing Variability scores. These scores were not significantly correlated which indicates that the strongest reflection of change in self-esteem was not demonstrated.

3) There is a positive correlation between the increase in self-esteem and the increase in reading comprehension among low level reading adults.

The relationship between the two variables was not demonstrated as significant, although when examining work status and hearing status, there was a significant correlation with change in Total Positive scores.

The limitations of the study, especially the inappropriateness of the TSCS with the sample population, the short length of the study, and the small sample size, 
were important hindering factors. However, despite the limitations, the following conclusion can be drawn.

1) Adult reading levels are improving while subjects are participating in the $\mathrm{ABE}$ program.

since self-esteem remains a critical component in educational achievement as demonstrated in past research, repetition of this study should be conducted considering the limitations outlined. The following recommendations are indicated.

1) Use a larger sample size of at least 30 subjects or more if possible. Otherwise, a case study format might be appropriate to examine the relationship between reading comprehension and self-esteem in the low level reading adult population.

2) Lengthen the time of the study to a minimum of two terms in order to increase the likelihood of identifying possible changes, especially in self-esteem.

3) Limit the study to hearing subjects to obtain baseline information for the hearing segment of the population.

4) Include equal numbers of employed and unemployed subjects to confirm the significance of employment status as an important factor in relation to self-esteem.

5) Investigate other self-esteem inventories and instruments to determine whether there is another instrument appropriate to low level reading adults or develop an 
instrument specific to this population. Prior to the study, thoroughly pilot test the instruments with the population to insure applicability to undereducated adults and insure that the administering procedures run smoothly.

6) Rather than evaluate general self-esteem levels, locate or create an instrument that is specific to the evaluation of self-esteem in a contextual relationship to the subject as a learner. A determination of self-esteem levels that indicate self-perceptions of the individual as a student would give more specific information than general self-esteem.

7) Investigate other reading assessments that are designed to test adult, not child, reading levels. This includes adult interest subject material written at levels primer to ninth grade. The print should be large, and the comprehension check should be presented in a simple, nonthreatening format. The reading test should measure progress in small, partial year increments.

Self-esteem is a difficult construct to measure. Selfreporting self-esteem information is problematic due to a myriad of possible contaminating variables (Wylie, 1961). Additionally, self-esteem is a variable that resists change and attempts to maintain itself, positively or negatively (Purkey, 1970). The difficulties encountered in assessing self-esteem might indicate that the study subjects were unfamiliar with the concepts involved in self-evaluation. 
Observational approaches or a case study format might produce different information; however, self-report remains the best technique to measure self-esteem (Burns, 1979). with proper pre-study instruction, the population under study could be introduced to self-evaluation issues. Instruction could help them begin thinking about their selfperceptions. In this way, the actual testing would more accurately reflect self-reported self-esteem levels.

My subjective speculations remain that self-esteem is a highly critical factor in adult education particularly with the segment of the population researched in this project. I suggest that the Community College system and other agencies handling literacy development conduct more extensive classbased research in this area. Furthermore, I recommend that practitioners incorporate self-esteem enhancing activities into their curriculum. These activities can be individualized activities or group efforts. In addition to commercially available materials, teacher created ideas are often more specific to the individual class configurations. Additionally, support groups can be encouraged within the classrooms to create more supportive systems and interdependent relationships among the adults. Often, the academic skills this population lacks creates a sense of isolation and despondency. It is more encouraging to create an atmosphere that is supportive and positive in confirming the importance of how a person evaluates his/her self-worth. 
The comprehensive research and resulting conclusions documenting the significance of the relationship between self-esteem and achievement coupled with rising rates of illiteracy, indicate an area of study that deserves more attention. There is a proliferation of programs designed to improve literacy rates, and these programs need more information regarding the effectiveness of instruction. Literacy programs need to be structured to meet the needs of the low level reading adult learner both cognitively and affectively. Adult educators will be better equipped to teach effectively as issues connecting success to methodology are researched and applied to practice. 
Bakke, E. W. (1933). The unemployed man: A social study. London: Nisbet \& Co.

Balmuth, M. (1986). Essential characteristics of effective adult literacy programs: A review and analysis of the research. Final Report for the Adult Beginning Reader Project. New York: New York state Department of Education.

Bentler, P. M., Suinn, R. M. (1972). "Review of Tennessee Self Concept Scale". In Mental Measurements Yearbook. Ed. O. K. Buros. 7th ed. New Jersey: The Gryphon Press.

Bowren, F. R., \& Zintz, M. V. (1977). Teaching reading in adult basic education. Debuque, IA: William C. Brown.

Brigance, A. H. (1983). Comprehensive inventory of basic skills. North Billerica, MA: Curriculum Associates.

Brookfield, S. D. (1986). Understanding and facilitating adult learning. San Francisco: Jossey-Bass.

Brookover, W. B., Thomas, S. \& Paterson, A. (1964). Selfconcept of ability and school achievement. Sociology of Education, 27, 271-279.

Burns, R. B. (1979). The self concept in theory. measurement, development and behavior. New York: Longman.

Buros, O. K. (Ed.) . (1972). Mental measurements yearbook (Vol. 1, 7th edition). Highland Park, NJ: Gryphon Press.

Coopersmith, S. (1967). The Antecedents of self esteem. San Francisco: W. H. Freeman.

Curtis, A. C. (1982-1983). A study of the effects of process-oriented reading instruction and self-concept enhancement on reading achievement among community college students. Dissertation Abstracts International, $43(7-12), 6 \mathrm{~A}$. (ERIC Document Reproduction Service No. ED 230 926) 
Darkenwald, G. G. (1980). Continuing education and the hardto-reach adult. In G. G. Darkenwald, G. A. Larson, \& A. B. Knox (Eds.), Reaching hard-to-reach adults: New directions for continuing education (pp. 1-10). San Francisco: Jossey-Bass.

Davisson, J. M. (1979). Differential effect of the college student's self concept level on reading gains in two methods of reading instruction. Dissertation Abstracts International, $40(1-6)$, 5A. (ERIC Reproduction Service No. ED 181-414)

Farrugia, D., \& Austin, G. F. (1980). A study of socialemotional adjustment patterns of hearing-impaired students in different educational settings. American Annals of the Deaf, 125(5), 535-541.

Fingeret, A. (1983). Social network: A new perspective on independence and illiterate adults. Adult Education Quarterly, 33(3), 133-146.

Fingeret, A. (1984). Adult literacy education: current and future directions. (Report No. CE 039 454). Columbus, $\mathrm{OH}$ : National Institute of Education. (ERIC Document Reproduction Service No. ED 246 308)

Fitts, W. H. (1964). Tennessee self concept scale. Los Angeles, CA: Western Psychological Services.

Garrison, W. M., Tesch, S., \& DeCaro, P. (1978). An assessment of self-concept levels among postsecondary deaf adolescents. American Annals of the Deaf, 123, 968-975.

Gay, L. R. (1987). Educational research: Competencies for analysis and application (3rd ed.). Columbus, $\mathrm{OH}$ : Merrill.

Hadley, H. R. (1988). Improving reading scores through a self-esteem intervention program. Elementary School Guidance and Counseling, 22, 248-252.

Hansford, B. C., \& Hattie, J. A. (1982). The relationship between self and achievement/performance measures. Review of Educational Research, 52(1), 123-142.

Harris, L. and Associates, Inc. (1970). Survival literacy study. (Report No. AC 012 934). Washington DC: National Reading Council. (ERIC Reproduction Service No. ED 068 813). 
Harris, L. and Associates, Inc. (1971). The 1971 national reading difficulty index: A study of functional reading ability in the U.S. for the National Reading center. (Report No. AC 012 159). Washington DC: National Reading Center Foundation. (ERIC Reproduction Service No. ED 057312 ).

Hayes, E. R. (1988). A typology of low-literate adults based on perceptions of deterrents to participation in adult basic education. Adult Education Quarterly, $\underline{39}(1), 1-$ 10 .

Hunter, C. S. J., \& Harman, D. (1979). Adult illiteracy in the United States: A report to the Ford Foundation. New York: McGraw-Hill.

Imel, s., \& Grieve, s. (n.d.) Adult literacy education. Columbus, $\mathrm{OH}$ : National Center for Research in Vocational Education. (ERIC Digest No. 40).

Jones, E. V. (1981). Reading instruction for the illiterate adult. Chicago: American Library Association.

Jones, J. G., \& Grieneeks, L. (1970). Measures of selfperception as predictors of scholastic achievement. Journal of Educational Research, 63(5), 201-203.

Kidd, J. R. (1959). How adults learn. New York: Association Press.

Knowles, M. (1970). The modern practice of adult education: Andragogy versus pedagogy. New York: Association Press.

Knowles, M., and Associates (1984). Andragogy in action. San Francisco: Jossey-Bass.

Knox, A. B. (1977). Adult development and learning. (1st ed.). San Francisco: Jossey-Bass.

Komarovsky, M. (1940). The unemployed man and his family: The effect of unemployment upon the status of the man in fifty-nine families. New York: Dryden Press.

Kozol, J. (1985). Illiterate America. New York: New Library America.

Larson, J. H. (1984). The effect of husband's unemployment on marital and family relations in blue-collar

families. Family Relations, 33, 503-511. 
Lawrence, D. (1985). Improving self-esteem and reading. Educational Research, 27(3), 194-200.

Marsh, H. W. (1984) . Relations among dimensions of selfattribution, dimensions of self-concept, and academic achievements. Journal of Educational Psychology, 76(6), 1291-1308.

Meadow, K. P. (1980, October). Self-concept, self-esteem and deafness: Research problems and findings. Paper presented at the Annual Convention of the American Psychological Association, Quebec, Canada (Report No. CG 015 124). (ERIC Document Reproduction Service No. ED 199 603)

Mills, C.N., Swerdlik, M. E. "Review of Brigance Diagnostic Comprehensive Inventory of Basic Skills". In Mental Measurements Yearbook. Ed. J. V. Mitchell. 9 th ed. Lincoln: University of Nebraska Press, 1985.

Mitchell, J. V., Jr. (Ed.). (1985). Mental measurements yearbook (Vols 1-2, 9th edition). Lincoln: University of Nebraska Press.

National Association for Public School Adult Education. (1967). Adult basic education: A quide for teachers and teacher trainers. Washington, DC: Author.

Northcutt, N. (1975). Adult performance level project: Adult functional competency: A report to the office of Education Dissemination Review Panel. Austin: University of Texas, Division of Extension.

Northwest Regional Laboratory. (1982). Northwesterners out of work: The human costs of unemployment (Research Rep. No. 400-80-0105). Portland, OR: National Institute of Education.

Oregon ABE Growth. (1987) . Oregon State Department of Community colleges.

Oregon Adult Basic Education: Fifteen year results. (1988). oregon state Department of Community colleges.

Patton, W., \& Roskos, K. (in press). Developing literacy through whole language in ABE settings: A report of research-in-progress. In Research in Education for Adult Learners, $1(1), 17-20$. 
Pendergast, M. A., \& Binder, D. M. (1975). Relationships of selected self-concept and academic achievement measures. Measurement and Evaluation in Guidance, $\underline{8}(2), 92-95$.

Perfetti, L. J., \& Bingham, W. C. (1983). Unemployment and self-esteem in metal refinery workers. Vocational Guidance Quarterly, 31(3), 195-201.

Pratt, G. K. (1933). Morale: The mental hygiene of unemployment. (7th ed.). New York: The National Committee for Mental Hygiene.

Purkey, W. W. (1970). Self concept and school achievement. Englewood Cliffs, NJ: Prentice-Hall.

Reder, S. M. (1985) . Giving literacy away: An alternative strategy for increasing adult literacy development. Portland, OR: Northwest Regional Educational Laboratory.

Roid, G. H. \& Fitts, W. H. (1988). Tennessee self-concept scale (revised manual). Los Angeles, CA: Western Psychological Services.

Scheirer, M. A., \& Kraut, R. E. (1979). Increasing educational achievement via self concept change. Review of Educational Research, $\underline{49}(1), 131-150$.

Shavelson, R. J., Hubner, J., \& Stanton, G. C. (1976). Selfconcept validation of construct interpretations. Review of Educational Research, 46(3), 407-441.

Smith-Burke, M. T. (1987). Starting over: Characteristics of adult literacy learners. New York: Literacy Assistance Center.

Super, D. E. (1957). The psychology of careers. New York: Harper and Row.

Thomas, J. B. (1980). The self in education. Windsor, England: NFER Publishing.

U.S. Department of Education, National Center for statistics. (1986). [Participants in adult basic education programs]. Unpublished data.

U.S. Department of Education. (n.d.) Fact Sheet on Nationwide Functional Literacy Initiative. Washington D.C.: Office of Vocational and Adult Education. 
Wirth, S. (1977). Effects of a multifaceted reading program on self-concept. Elementary School Guidance and Counseling, 12, 33-40.

Wlodkowski, R. J. (1985). Enhancing adult motivation to

learn. San Francisco: Jossey-Bass.

Wylie, R. C. (1961). The self concept: A critical survey of pertinent research literature. Lincoln: University of Nebraska Press.

Yamamoto, K. (Ed.). (1972). The child and his image: Self concept in the early years. Pennsylvania: Houton Mifflin. 
APPENDIX A

SELF-REPORTED STUDENT PROFILE 
Student Profile Information

Adult Basic Education Class/Portland Community college Fall term, 1989

Amount of time in program

$$
\begin{aligned}
& 0-2 \text { terms } \\
& 2 \text { terms to } 1 \text { year } \\
& 1-2 \text { years } \\
& 2 \text { years }+
\end{aligned}
$$

Current reading level

$$
\begin{aligned}
& 0-1 \text { grade level } \\
& 2-3 \text { grade level } \\
& 4-5 \text { grade level } \\
& 6 \text { and higher }
\end{aligned}
$$

Age of student

$$
\begin{aligned}
& 20-30 \text { years } \\
& 31-40 \text { years } \\
& 41-50 \text { years } \\
& 51 \text { and older }
\end{aligned}
$$

Educational background

Stopped in grades $1-6$

Stopped in grades $7-12$

Graduated high school

Grew up in another country

Attended a special education program

Employed

Yes

No

Receiving some type of assistance (SSI, disability, worker's compensation)

$$
\text { Yes }
$$

No

Do you have any type of disability?

Yes

No

Kinds of disabilities identified by students

Hearing-impaired

Speech-impaired

Mental illness

Job-related illness

Developmentally disabled

other 
APPENDIX B

TENNESSEE SELF CONCEPT SCALE AND ANSWER SHEET 


\title{
Tennessee Self-Concept Scale
}

\author{
William H. Fitts, Ph.D.
}

Aublishod by

WPS

\section{INSTRUCTIONS}

On the top line of the separate answer sheet, fill in your name and the other information except for the time information in the last thife boxes. You will fill in these boxes later. Write only on the answer streef. 09 not put any marks in this booklet.

The statements in this booklet are to help you describe yqurself as you see yourself. Please respond to them as if rou prere describing - vurself to yourself. Do not omit any item. Read each satement carefunly, then select one of the five responses listed beton an you answes theet, put a circle around the response you chose. If you waht tochange an answer after you have circled it, do not erase it burpuk an through the response and then circle the response you wan

When you are feady to stald, filgd the box on your answer sheet marked time startetand theod the yinte. When you are finished, record the time finished in the box on yooronswer sheet marked time finished.

As youstart, be sodre that your answer sheet and this booklet are lined up evenly efingt the item numbers match each other.

Remember, put a circle around the response number you have chosen for each statement.

\begin{tabular}{|c|c|c|c|c|}
\hline $\begin{array}{c}\text { Completely } \\
\text { False }\end{array}$ & $\begin{array}{c}\text { Mostly } \\
\text { False }\end{array}$ & $\begin{array}{c}\text { Partly Faise } \\
\text { and } \\
\text { Partly True }\end{array}$ & $\begin{array}{c}\text { Mostly } \\
\text { True }\end{array}$ & $\begin{array}{c}\text { Completely } \\
\text { True }\end{array}$ \\
\hline 1 & 2 & 3 & 4 & 5 \\
\hline
\end{tabular}

You will find these response numbers repeated at the top of each page to help you remember them.

Copynght $\bullet 1964$ oy William H. Fitts

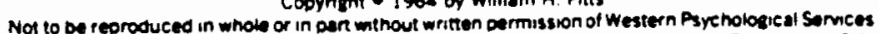
Not to be reproduced in whow or in pen minout whiten oermission of western Pyrenological Sorwces
All rights reserved.
123456789 


\begin{tabular}{|c|c|c|c|c|}
\hline $\begin{array}{c}\text { Completely } \\
\text { False }\end{array}$ & $\begin{array}{c}\text { Mostly } \\
\text { False }\end{array}$ & $\begin{array}{c}\text { Partly False } \\
\text { and } \\
\text { Partly True }\end{array}$ & $\begin{array}{c}\text { Mostly } \\
\text { True }\end{array}$ & $\begin{array}{c}\text { Completely } \\
\text { True }\end{array}$ \\
\hline 1 & 2 & 3 & 4 & 5 \\
\hline
\end{tabular}

Item
No.

1. I have a healthy body

1

3. I am an attractive person. 3

5. I consider myself a sloppy person 5

19. I am a decent sort of person 19

21. I am an honest person

23. I am a bad person

37. I am a cheerful person

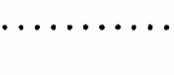




\begin{tabular}{|c|c|c|c|c|}
\hline $\begin{array}{c}\text { Completely } \\
\text { False }\end{array}$ & $\begin{array}{c}\text { Mostly } \\
\text { False }\end{array}$ & $\begin{array}{c}\text { Partly False } \\
\text { and } \\
\text { Partly True }\end{array}$ & $\begin{array}{c}\text { Mostly } \\
\text { True }\end{array}$ & $\begin{array}{c}\text { Completely } \\
\text { True }\end{array}$ \\
\hline 1 & 2 & 3 & 4 & 5 \\
\hline
\end{tabular}

$\begin{array}{cc}\text { Item } & \text { No. } \\ \text { No. }\end{array}$

2. I like to look nice and neat all the time

No.

4. I am full of aches and pains

4

6. I am a sick person

6

20. I am a religious person

20

22. I am a moral failure

$\ldots \ldots \ldots \ldots$

-

24. I am a morally weak person

38. I have a lot of self-control

40. I am a hateful person

on<smiles>CCC(C)C1CCCCC1CC</smiles>

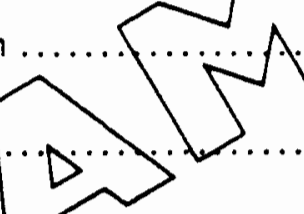

...

22

42. I am losing my mind...D

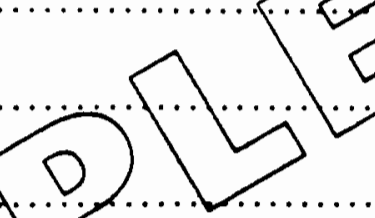

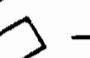

22

$+$

24

56. I am an important persoh to my friends and family $\ldots \ldots \ldots \ldots \ldots \ldots, 56$

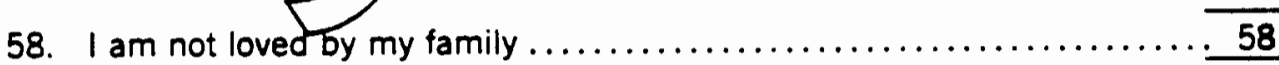

60. I feel that my family doesn't trust me $\ldots \ldots \ldots \ldots \ldots \ldots \ldots \ldots \ldots, 60$

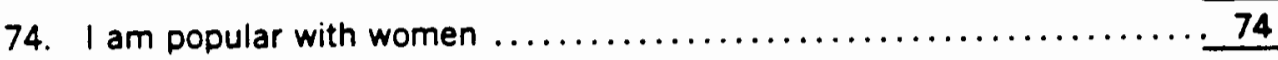

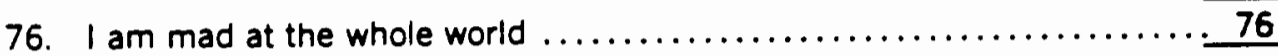

78. I am hard to be friendly with $\ldots \ldots \ldots \ldots \ldots \ldots \ldots \ldots \ldots \ldots \ldots \ldots \ldots \ldots \ldots \ldots, 78$

92. Once in a while 1 think of things too bad to talk about $\ldots \ldots \ldots \ldots \ldots .92$

94. Sometimes, when I am not feeling well, I am cross 94 


\begin{tabular}{|c|c|c|c|c|}
\hline $\begin{array}{c}\text { Completely } \\
\text { False }\end{array}$ & $\begin{array}{c}\text { Mostly } \\
\text { False }\end{array}$ & $\begin{array}{c}\text { Partly False } \\
\text { and } \\
\text { Partly True }\end{array}$ & $\begin{array}{c}\text { Mostly } \\
\text { True }\end{array}$ & $\begin{array}{c}\text { Completely } \\
\text { True }\end{array}$ \\
\hline 1 & 2 & 3 & 4 & 5 \\
\hline
\end{tabular}

Item

7. I am neither too fat nor too thin

No.

9. I like my looks just the way they are

7

9

11. I would like to change some parts of my body

11

25. I am satisfied with my moral behavior

25

27. I am satisfied with my relationship to God

27

29. I ought to go to church more

43. I am satisfied to be just what I am

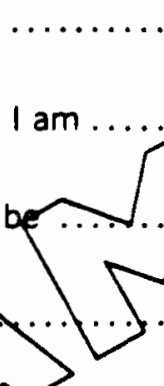

47. I despise myself<smiles>[C]1CCCCC1</smiles><smiles>CC(C)(C)c1ccccc1</smiles>

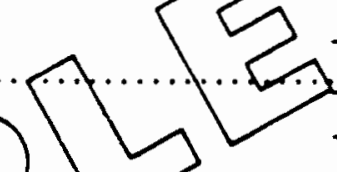
29

45. I am just as nice as I should

61. I am satisfied fanglly relationships

63. I understand $\sqrt{y}$ family as well as I should 63

65. I should trust my family more 65

79. I am as sociable as I want to be 79

81. I try to please others, but don't overdo it 81

83. I am no good at all from a social standpoint 83

95. I do not like everyone I know 95

97. Once in a while, $I$ laugh at a dirty joke 


\begin{tabular}{|c|c|c|c|c|}
\hline $\begin{array}{c}\text { Completely } \\
\text { False }\end{array}$ & $\begin{array}{c}\text { Mostly } \\
\text { Faise }\end{array}$ & $\begin{array}{c}\text { Partly False } \\
\text { and } \\
\text { Partly True }\end{array}$ & $\begin{array}{c}\text { Mostly } \\
\text { True }\end{array}$ & $\begin{array}{c}\text { Completely } \\
\text { True }\end{array}$ \\
\hline 1 & 2 & 3 & 4 & 5 \\
\hline
\end{tabular}

Item

8. I am neither too tall nor too short $\ldots \ldots \ldots \ldots \ldots \ldots \ldots \ldots \ldots \ldots \ldots, 8$

10. I don't feel as well as i should $\ldots \ldots \ldots \ldots \ldots \ldots \ldots \ldots \ldots \ldots \ldots, \ldots \ldots \ldots$

12. I should have more sex appeal $\ldots \ldots \ldots \ldots \ldots \ldots \ldots \ldots \ldots \ldots \ldots \ldots$

26. I am as religious as I want to be

26

28. I wish I could be more trustworthy

28

30. I shouldn't tell so many lies

44. I am as smart as I want to be

46. I am not the person I fould like to

48. I wish I didn't givgup as etasily as I do

48 30

62. I treat my pajentsas well as I should (Use past tense if parents are not living) 62

64. I am too sensitive to things my family says 64

66. I should love my family more 66

80. I am satisfied with the way I treat other people 80

82. I should be more polite to others 82

84. I ought to get along better with other people 84

96. I gossip a little at times 96

98. At times / feel like swearing 


\begin{tabular}{|c|c|c|c|c|}
\hline $\begin{array}{c}\text { Completely } \\
\text { False }\end{array}$ & $\begin{array}{c}\text { Mostly } \\
\text { False }\end{array}$ & $\begin{array}{c}\text { Partly Faise } \\
\text { and } \\
\text { Partly True }\end{array}$ & $\begin{array}{c}\text { Mostly } \\
\text { True }\end{array}$ & $\begin{array}{c}\text { Completely } \\
\text { True }\end{array}$ \\
\hline 1 & 2 & 3 & 4 & 5 \\
\hline
\end{tabular}

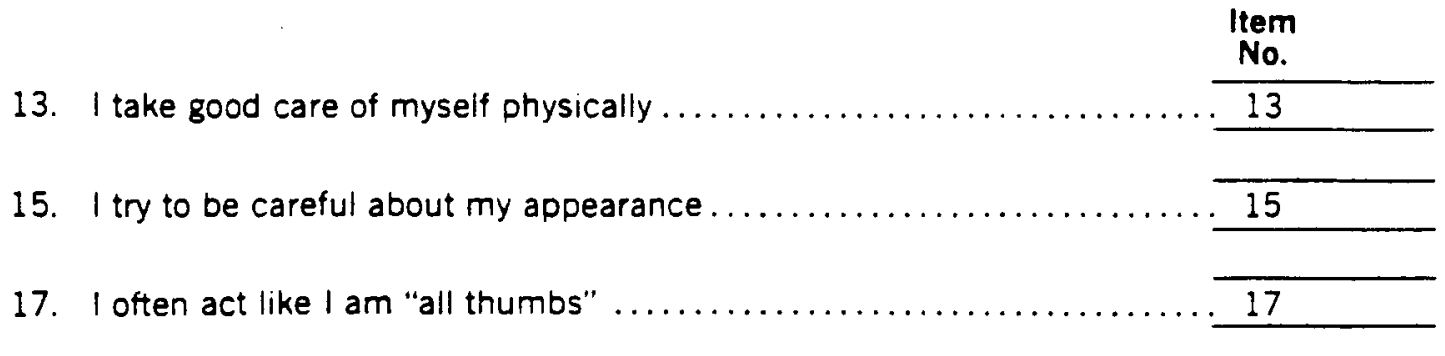

31. I am true to my religion in my everyday life

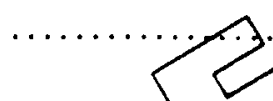

33. I try to change when I know I'm doing things that are whong \begin{tabular}{l}
\hline 31 \\
\hline 33 \\
\hline 35 \\
\hline 49 \\
\hline
\end{tabular}

35. I sometimes do very bad things.

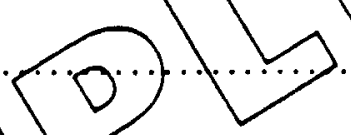

49. I can always take care of myself in and situation

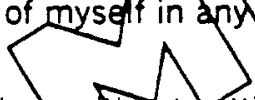

51. I take the blamg rox things without getting mad 51

53. I do things withput thiaking about them first 53

67. I try to play fair with my friends and family 67

69. I take a real interest in my family 69

71. I give in to my parents (Use past tense if parents are not living) 71

85. I try to understand the other fellow's point of view 85

87. I get along well with other people 87

89. I do not forgive others easily 89

99. I would rather win than lose in a game 


\begin{tabular}{|c|c|c|c|c|}
\hline $\begin{array}{c}\text { Completely } \\
\text { False }\end{array}$ & $\begin{array}{c}\text { Mostly } \\
\text { False }\end{array}$ & $\begin{array}{c}\text { Partly False } \\
\text { and } \\
\text { Partly True }\end{array}$ & $\begin{array}{c}\text { Mostly } \\
\text { True }\end{array}$ & $\begin{array}{c}\text { Completely } \\
\text { True }\end{array}$ \\
\hline 1 & 2 & 3 & 4 & 5 \\
\hline
\end{tabular}

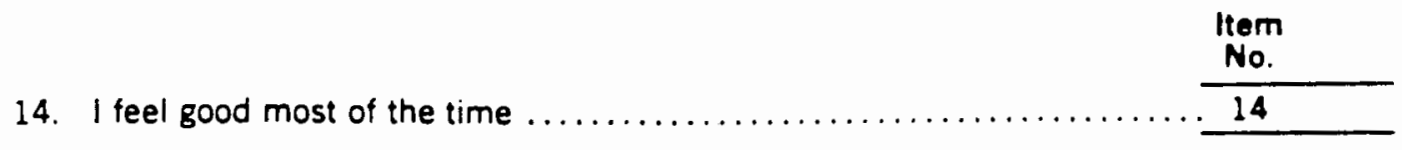

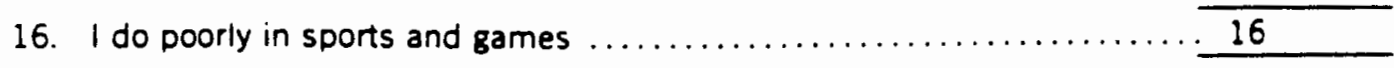

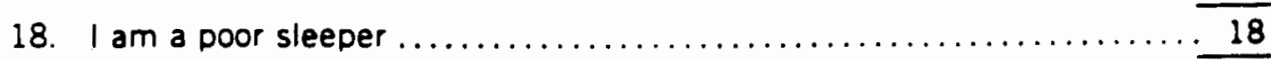

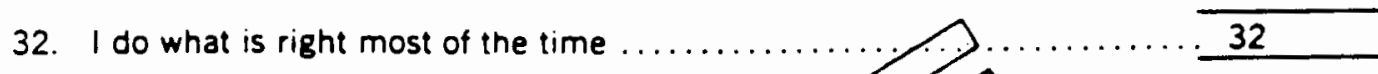

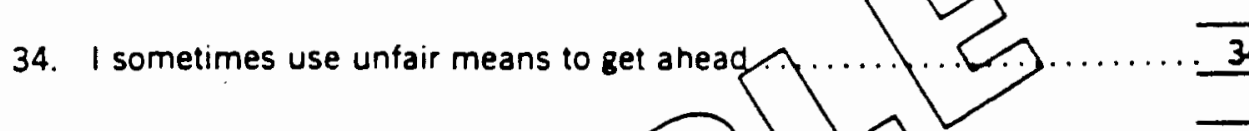

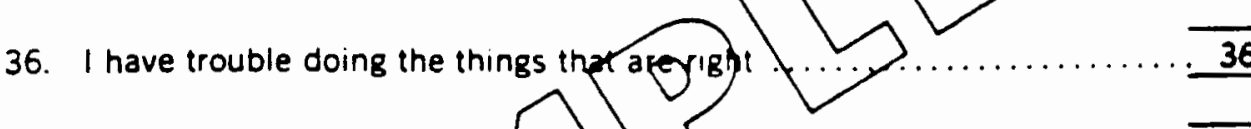

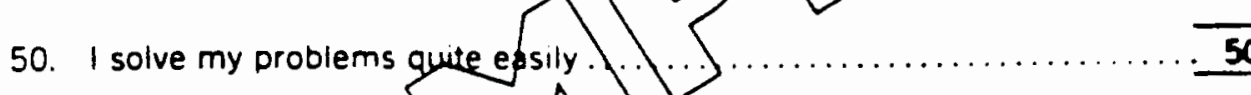

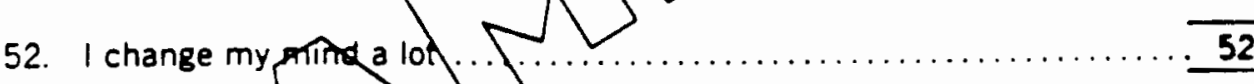

54. 1 in todan ayay prom probiems ......................... 5

68. I do mptshore of work at home $\ldots \ldots \ldots \ldots \ldots \ldots \ldots \ldots \ldots \ldots \ldots .68$

70. I quarrel with my family ........................... 70

72. I do not act like my family thinks I should

$\pi$

86. I see good points in all the people I meet

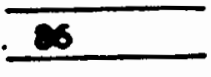

88. I do not feel at ease with other people

90. I find it hard to talk with strangers

100. Once in a while I put off unfil tomorrow what l ought 10 do today 

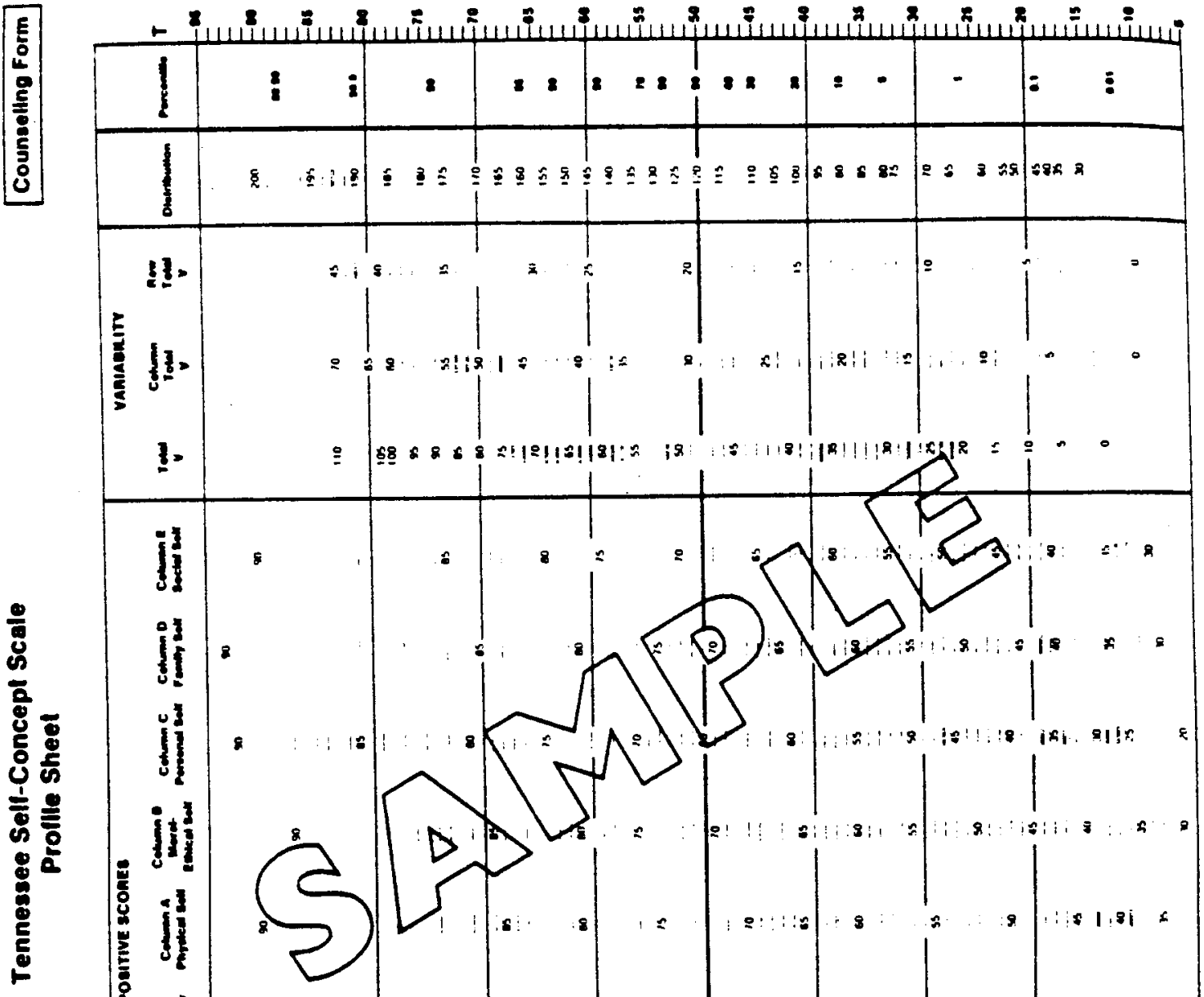

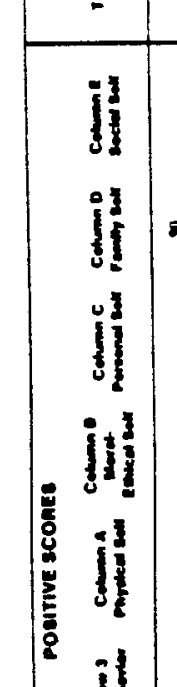

i]

in)

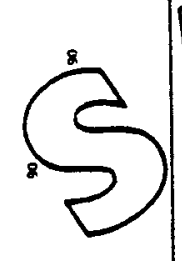

$?$

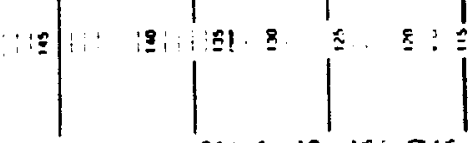




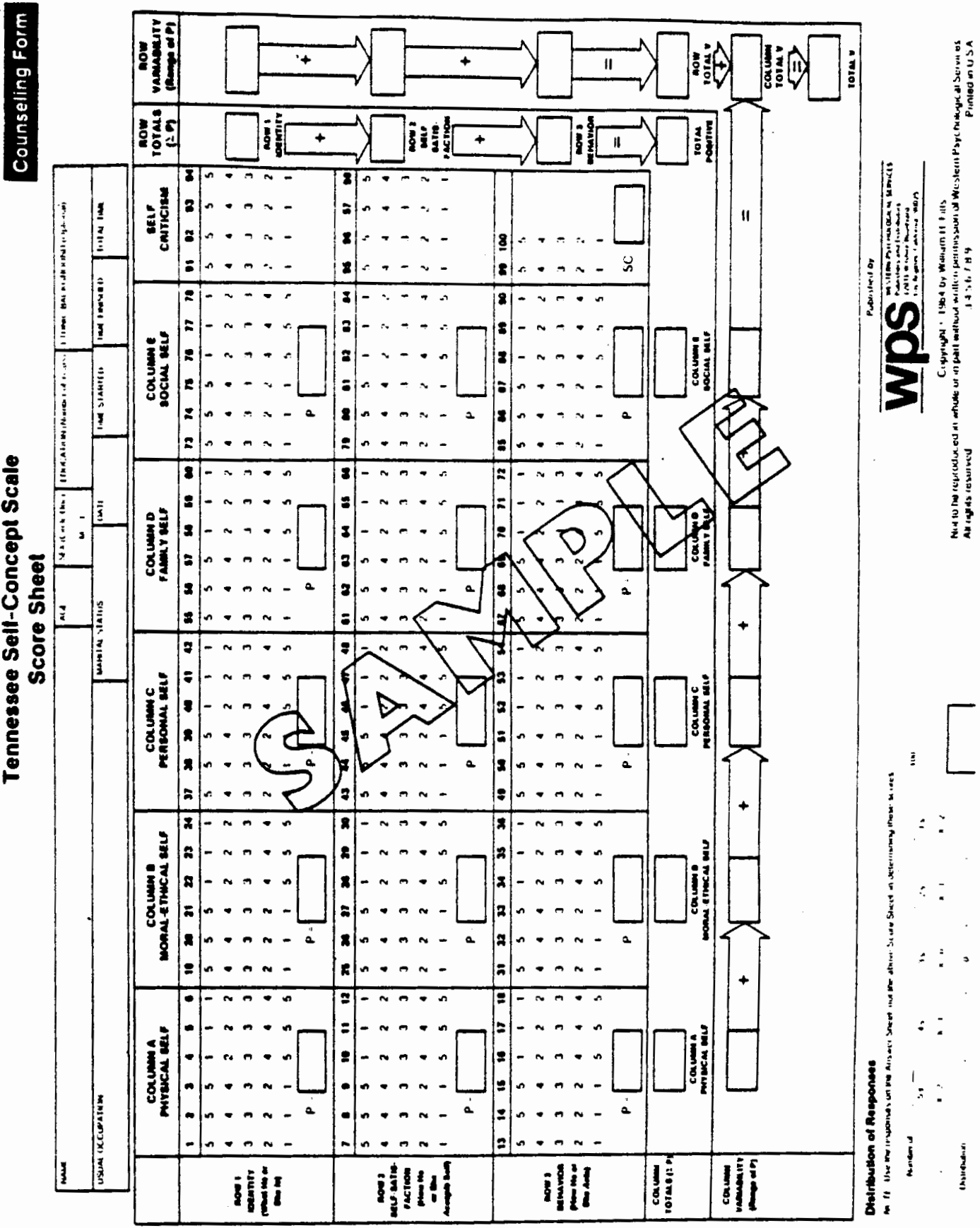


APPENDIX C

TEST-RETEST RELIABILITY OF MAJOR TSCS SCORES 
Test-Retest Reliability of the Major TSCS Scores

\begin{tabular}{|c|c|c|c|}
\hline TSCS Score & $r$ & Conflict Subscore & $r$ \\
\hline SC & .75 & Net Conflict & \\
\hline$T F$ & .82 & Identity & .70 \\
\hline VET C & .74 & Satisfaction - & .78 \\
\hline TOT C & .74 & Behavior & .69 \\
\hline Total Score & .92 & Physical & .67 \\
\hline Identity & .91 & Moral-Ethical & .73 \\
\hline Satisfaction & .88 & Personal & .82 \\
\hline Behavior & .88 & Family & .75 \\
\hline Physical & .87 & Social & .65 \\
\hline Moral-Ethical & .80 & Total Conflict & \\
\hline Personal & .85 & Identity & .80 \\
\hline Family & .89 & Satisfaction & .64 \\
\hline Social & .90 & Behavior & .94 \\
\hline V TOT & .67 & Physical & .61 \\
\hline$\checkmark \mathrm{COL}$ & .73 & Moral-Ethical & .80 \\
\hline V ROW & .60 & Personal & .77 \\
\hline DIST & .89 & Family & .72 \\
\hline $5 s$ & .88 & Social & .68 \\
\hline 45 & .79 & & \\
\hline $3 s$ & .77 & & \\
\hline $2 s$ & .71 & & \\
\hline 1s & .88 & & \\
\hline DP & .90 & & \\
\hline GM & .87 & & \\
\hline PSY & .92 & & \\
\hline PD & .89 & & \\
\hline$N$ & .91 & & \\
\hline PI & .90 & & \\
\hline NDS & .90 & & \\
\hline Time & .89 & & \\
\hline
\end{tabular}

Tote. From Filts (1965). 
APPENDIX D

BRIGANCE COMPREHENSIVE INVENTORY OF BASIC SKILLS 

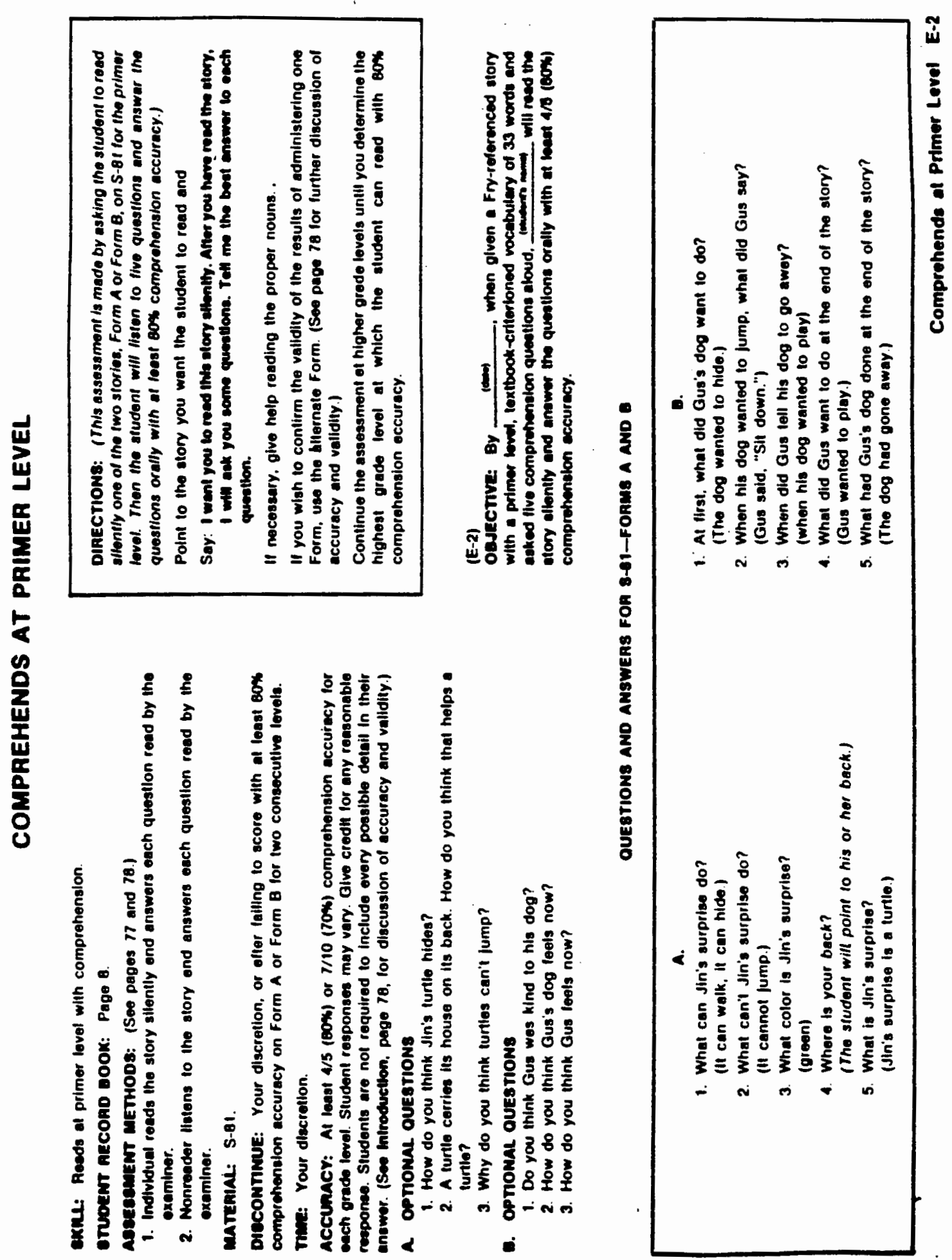


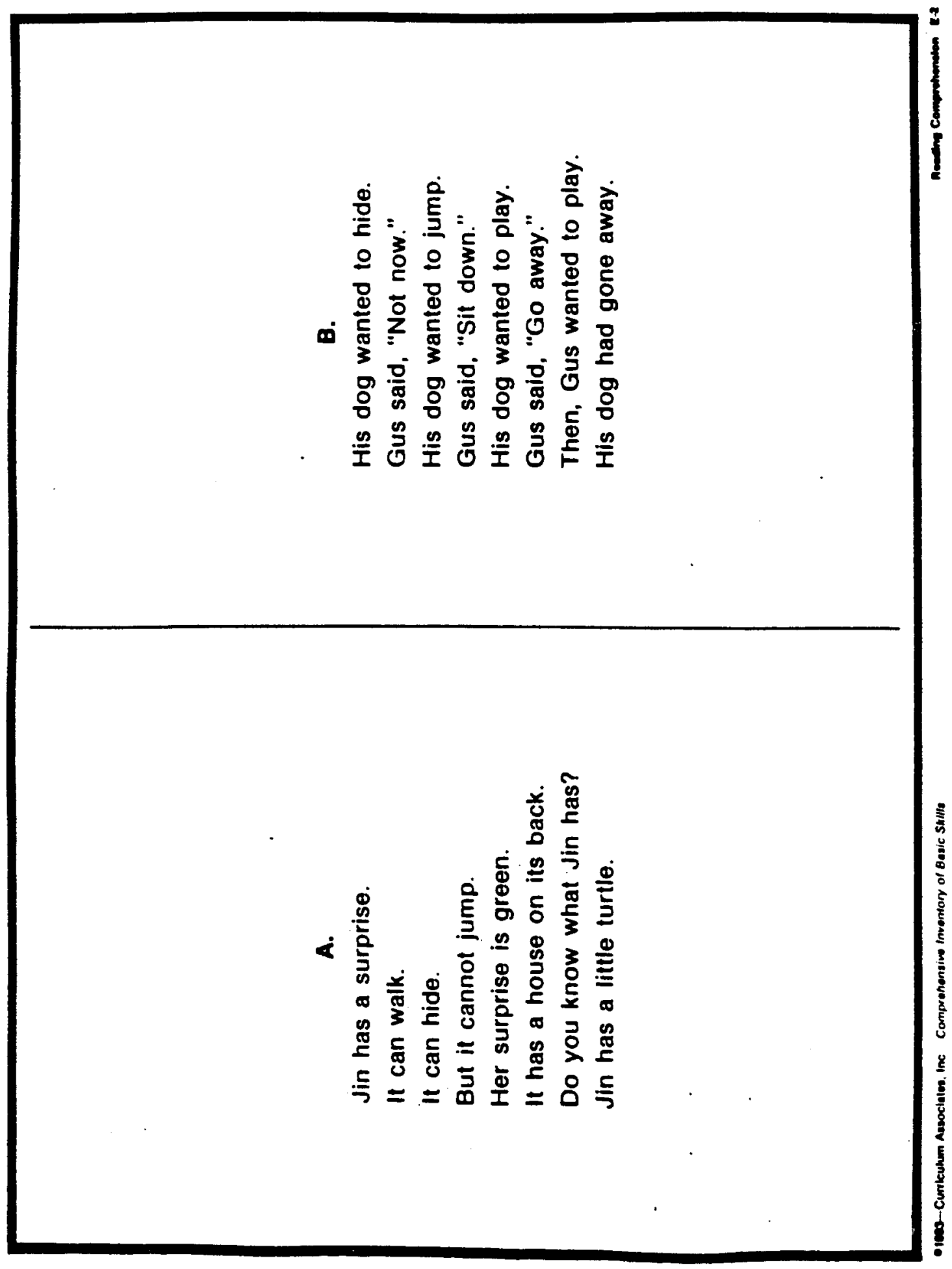




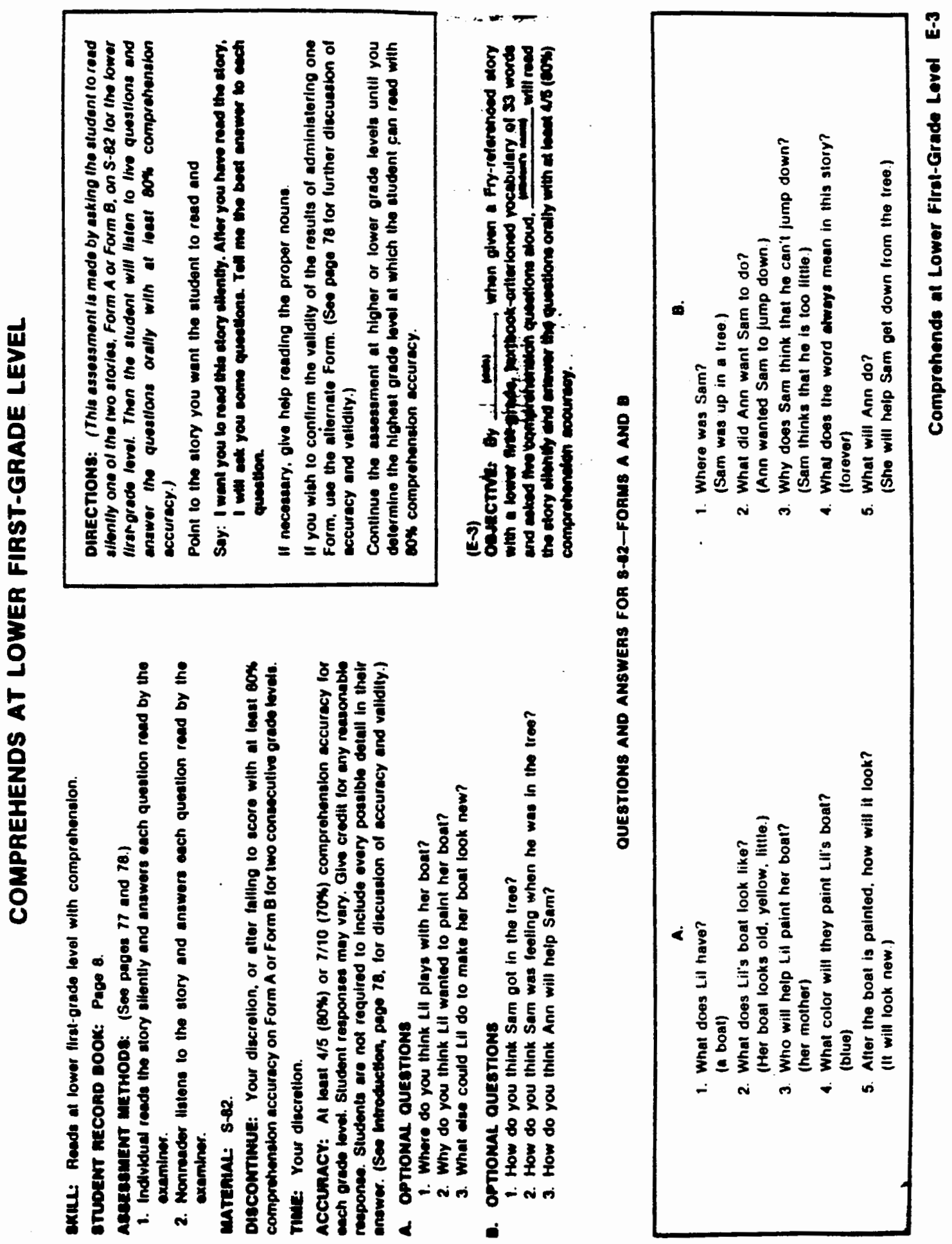




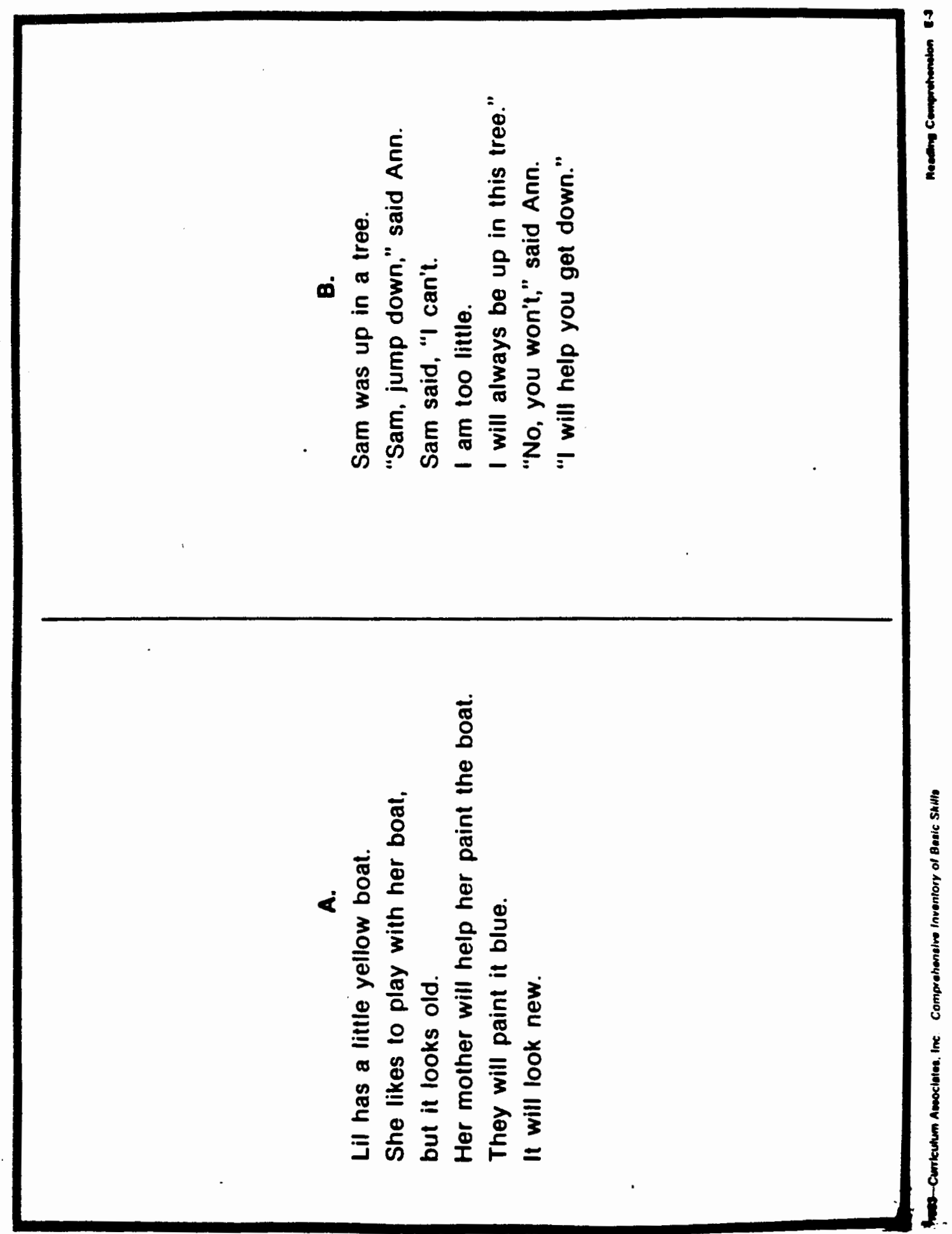



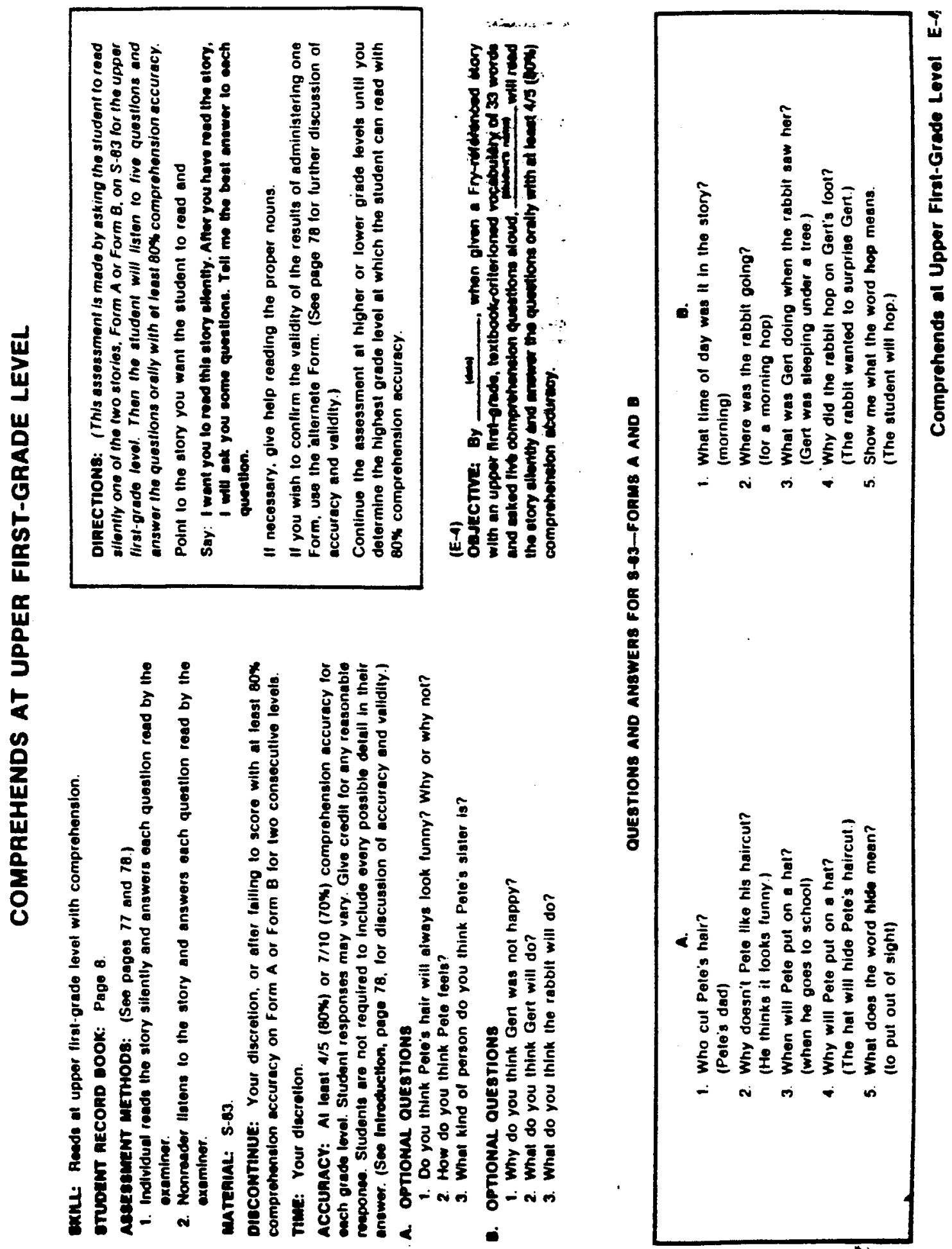


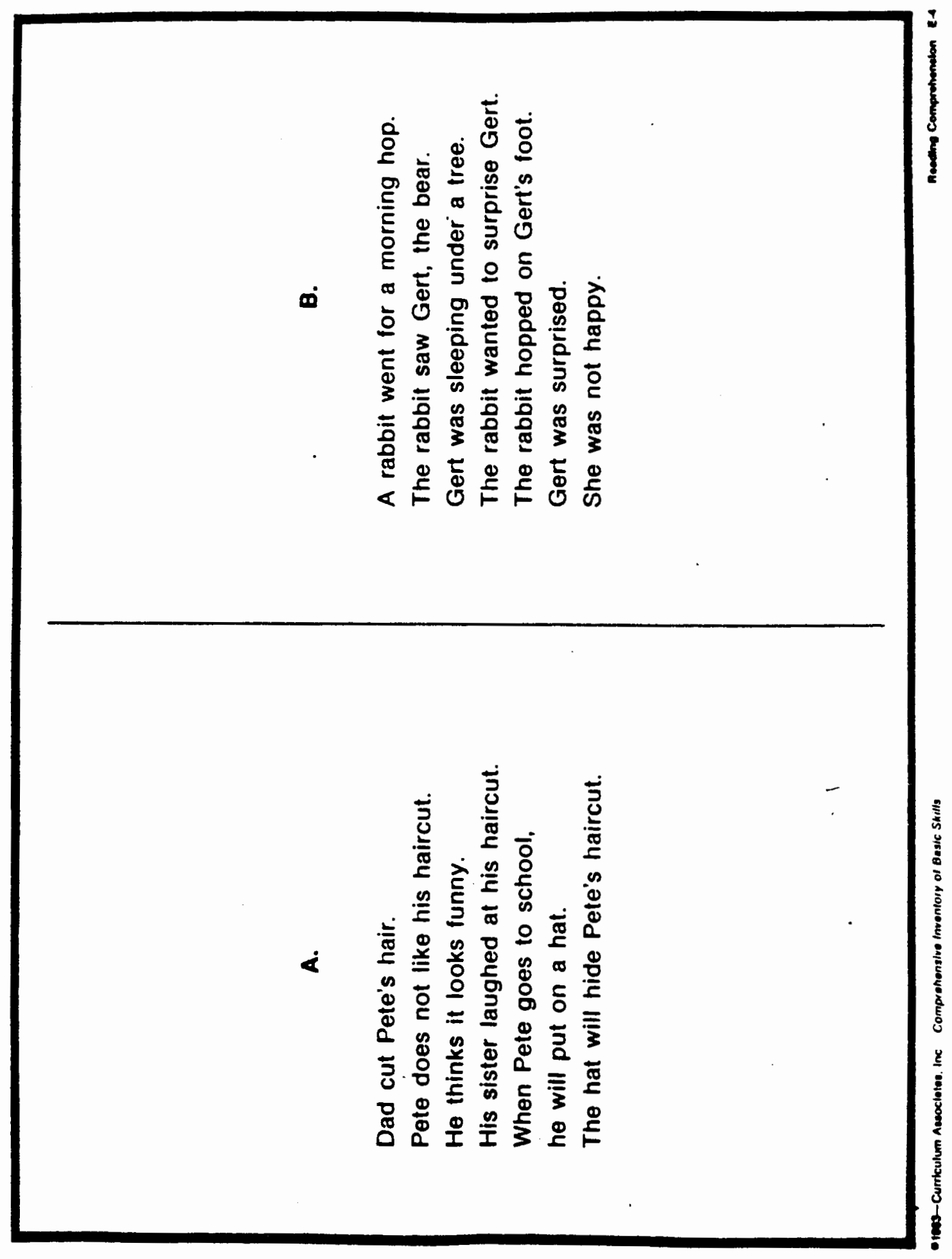




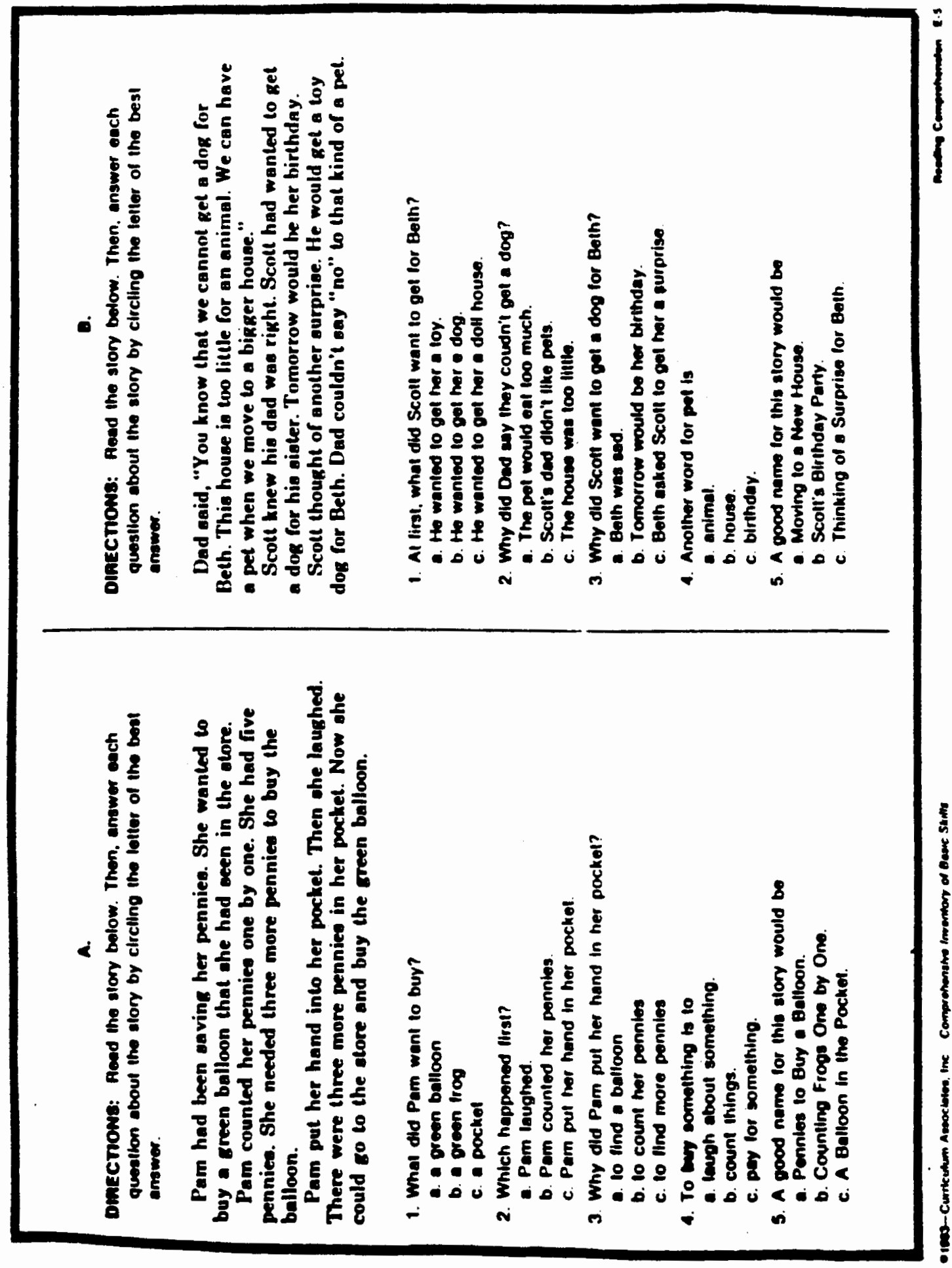




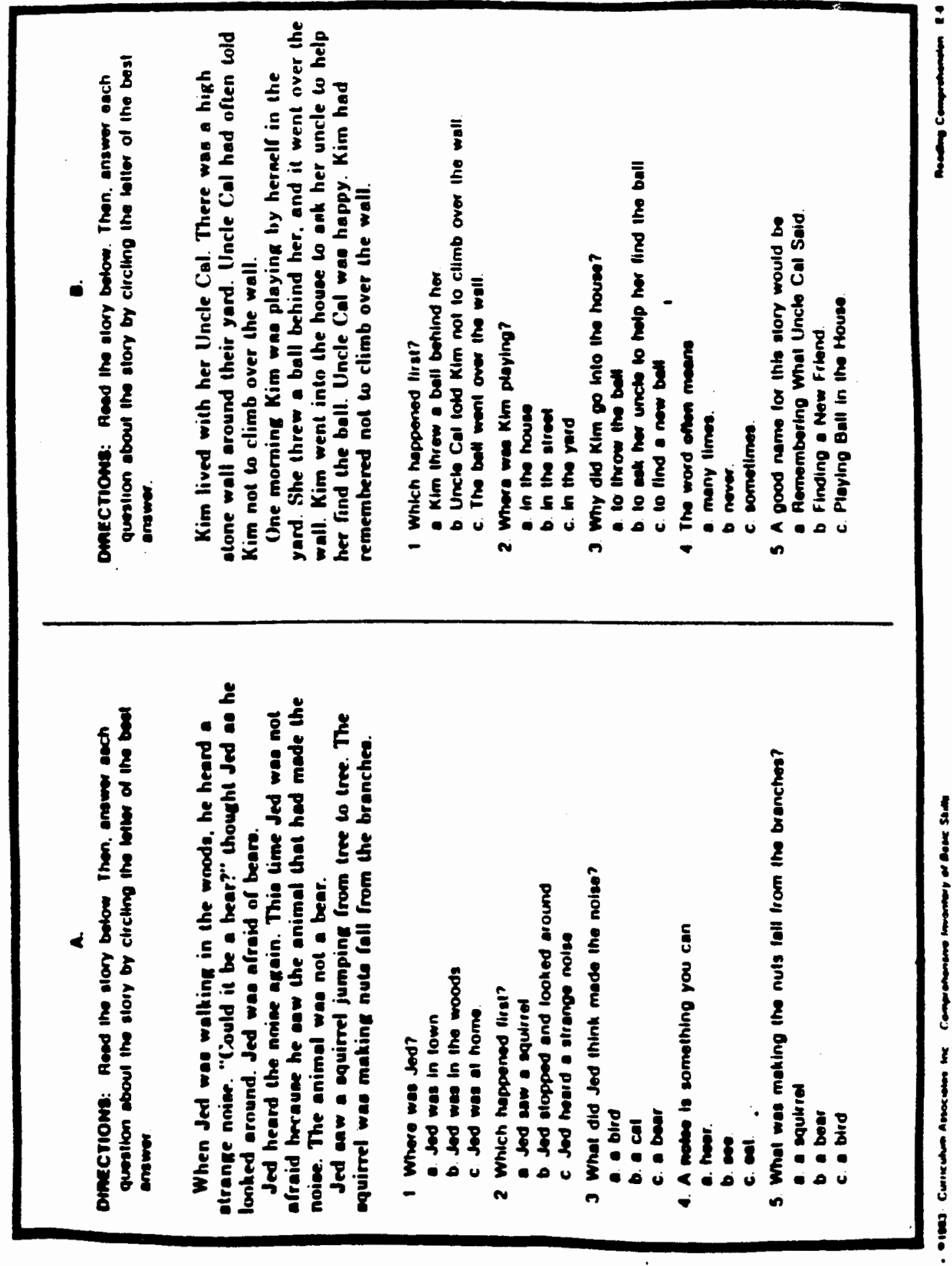




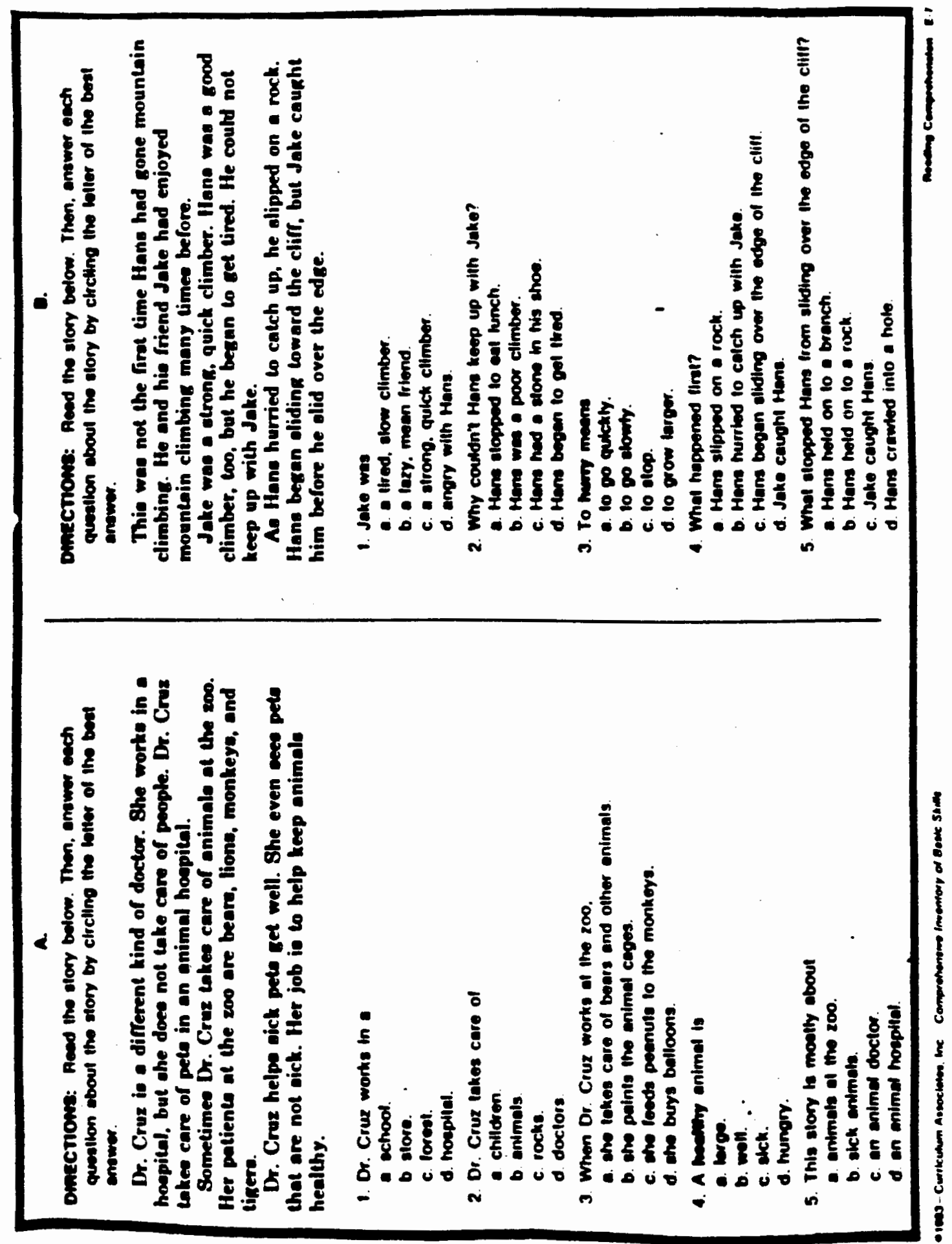




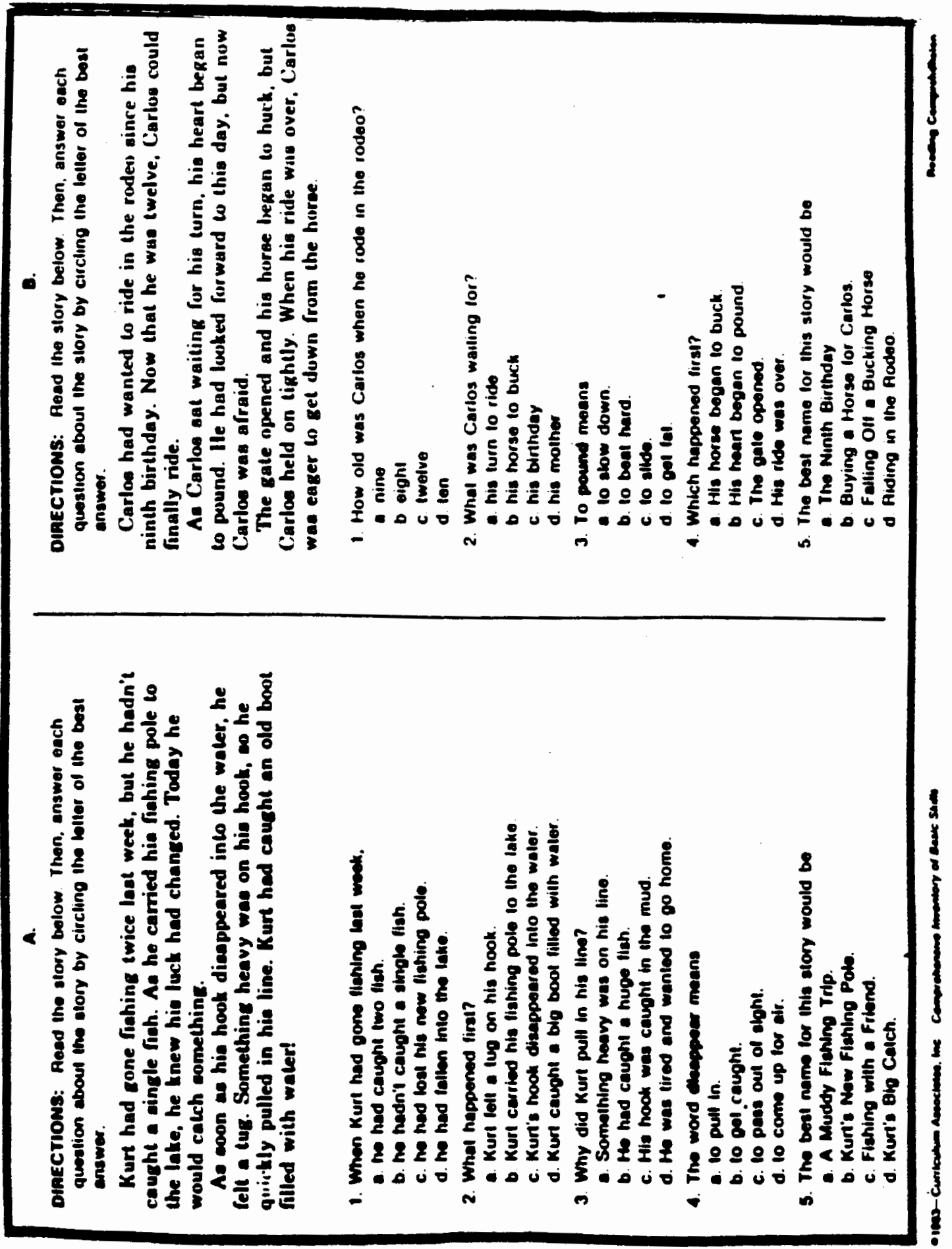




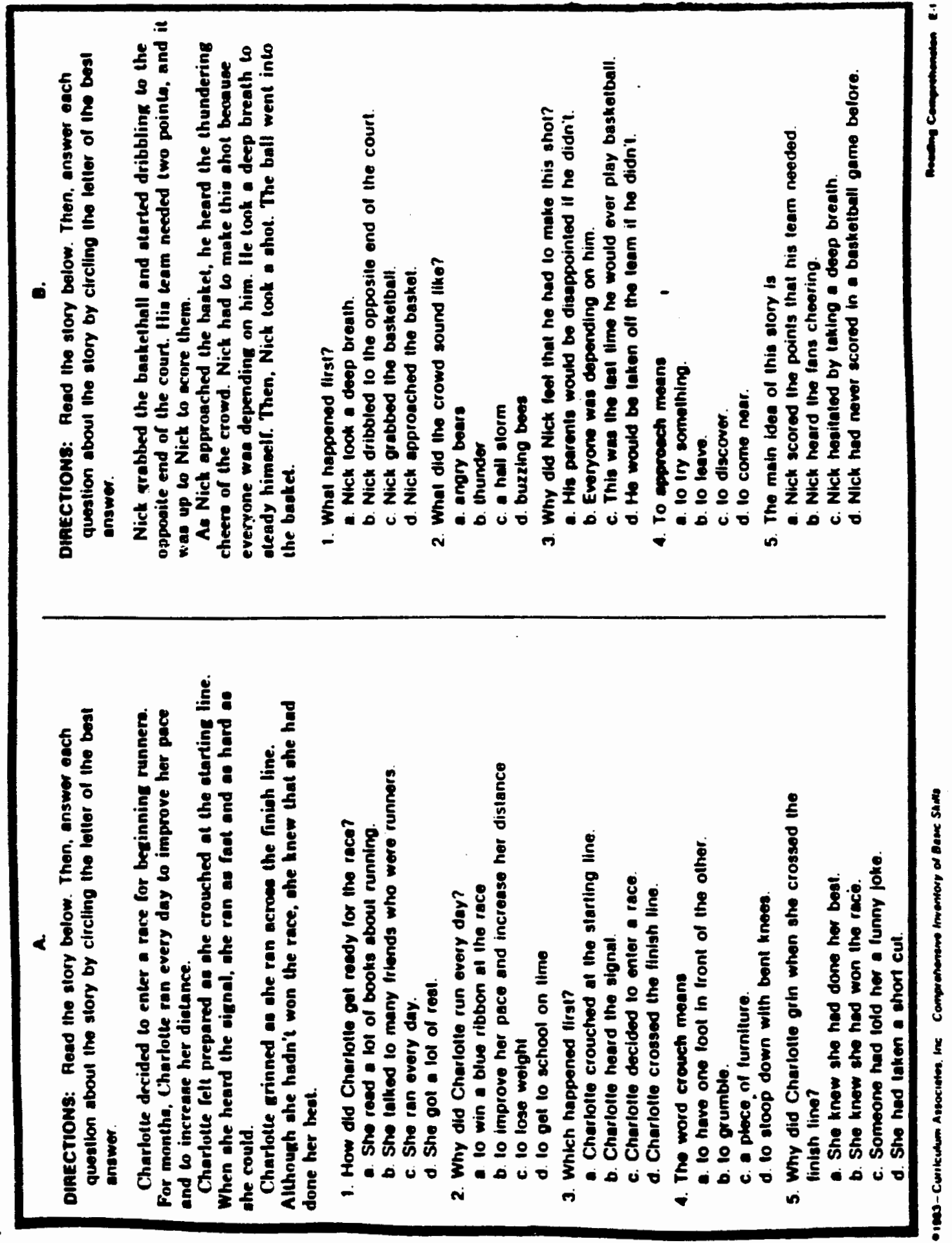




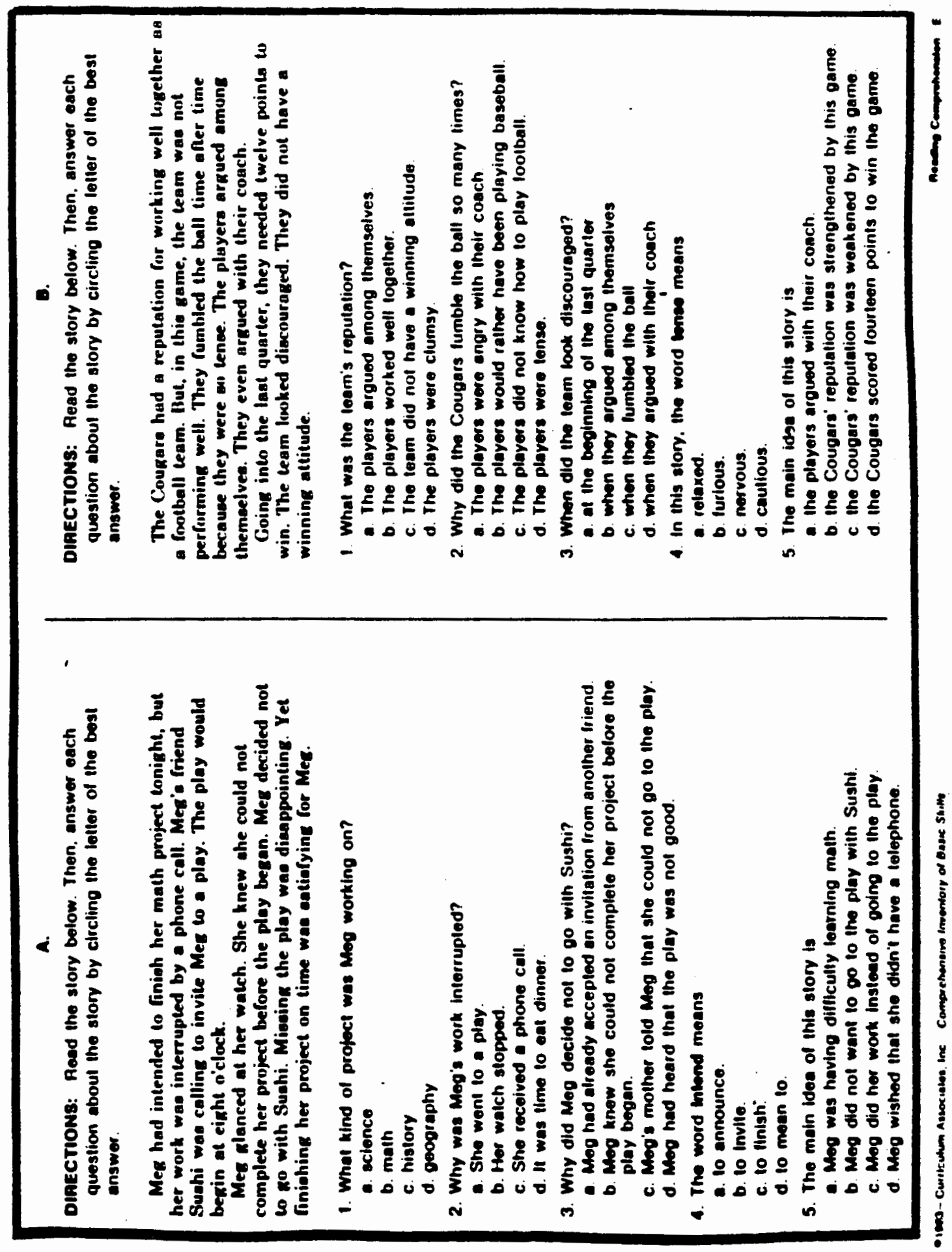




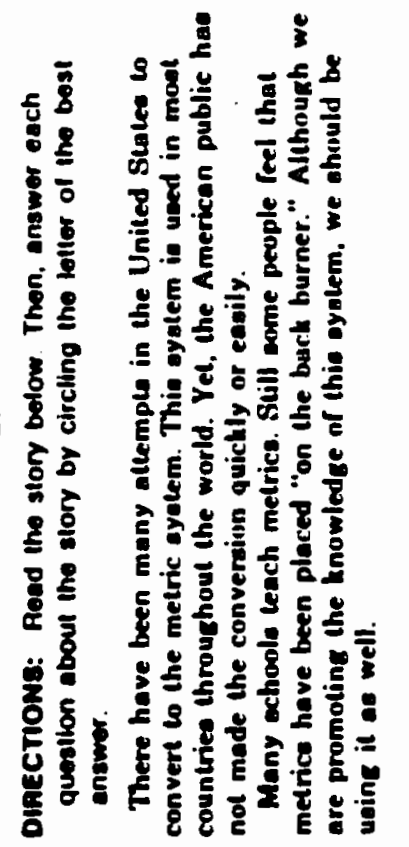

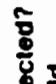

믈

势

$\xi$

产家

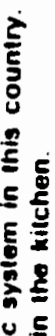

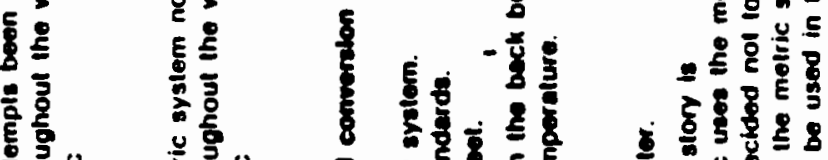

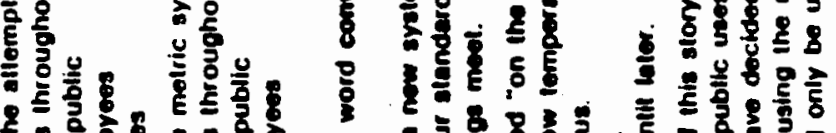

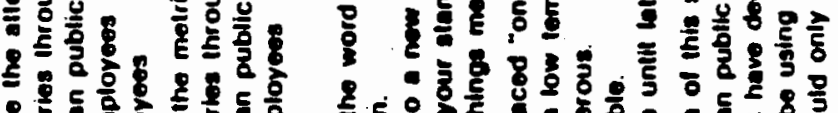

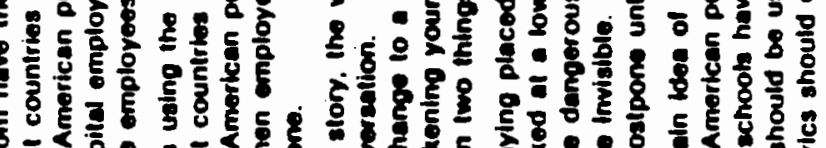

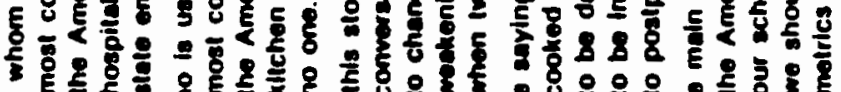

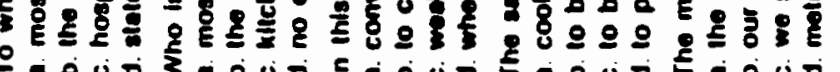
o.jut is
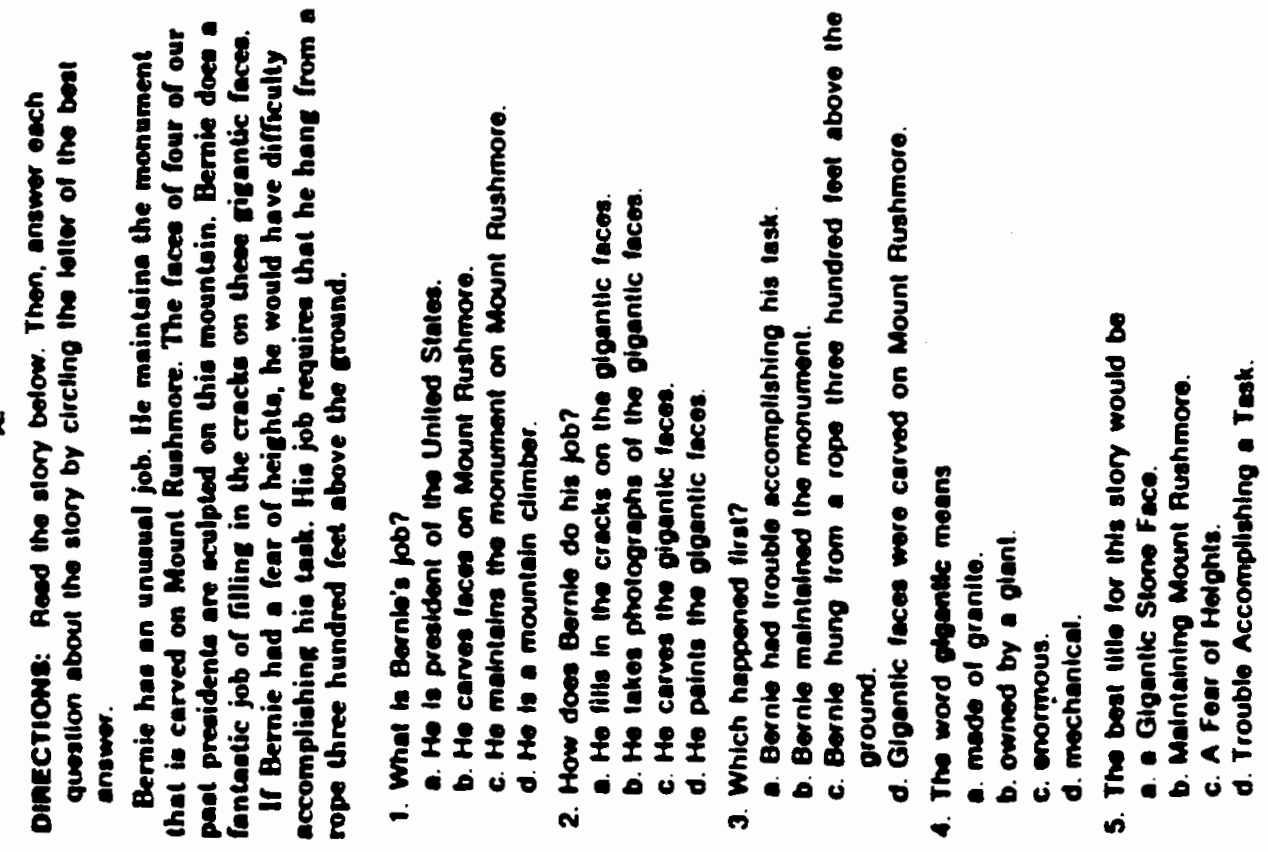


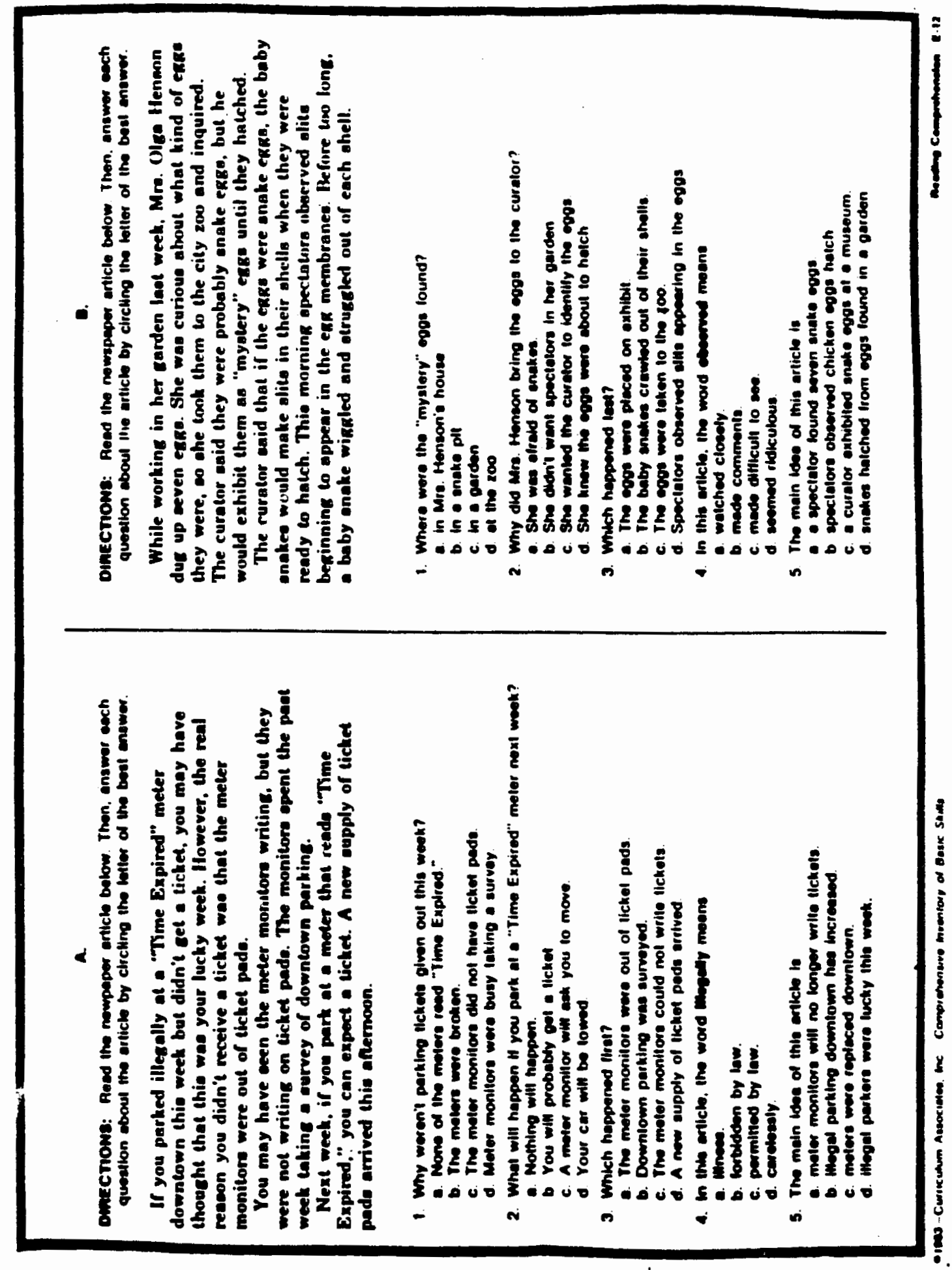




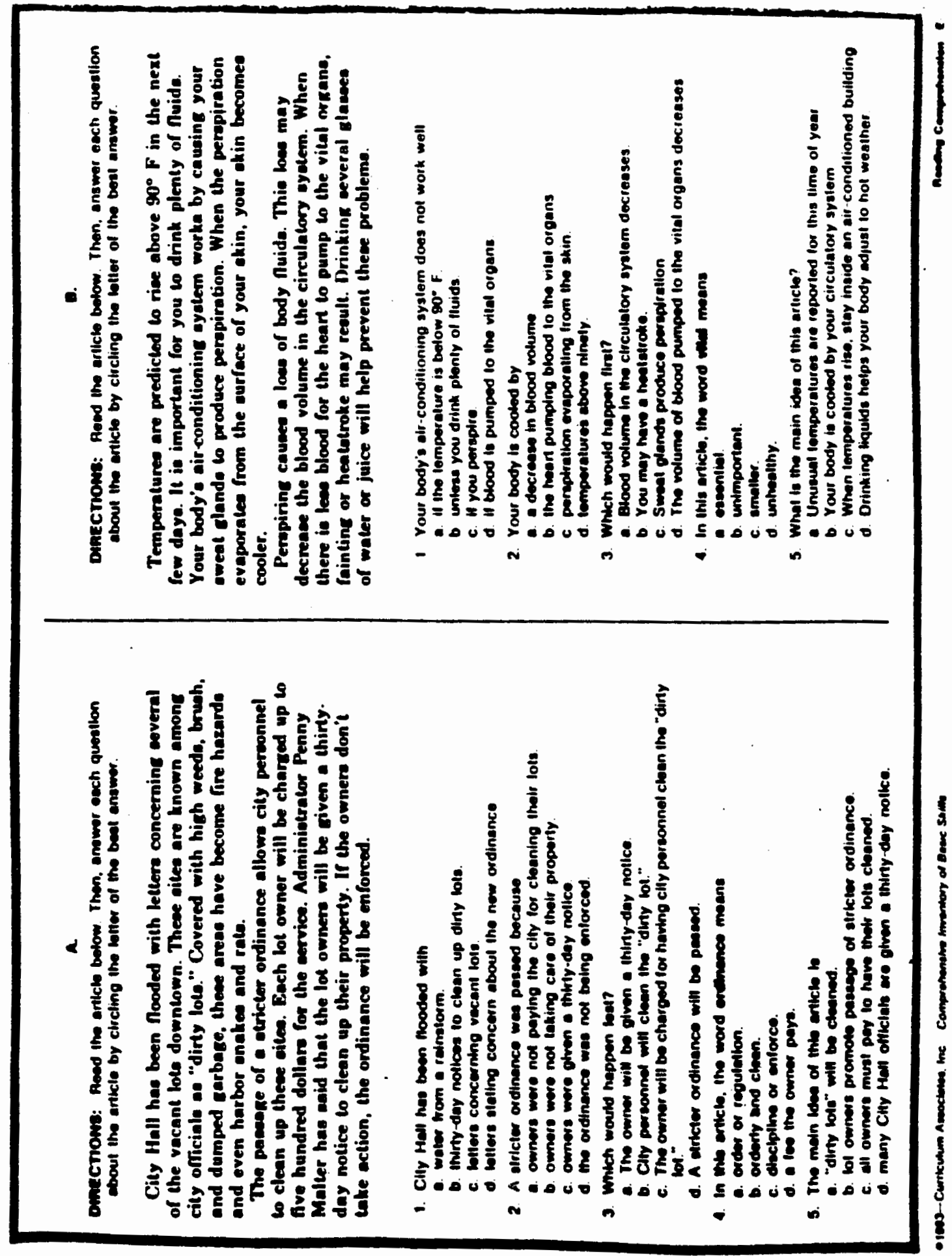



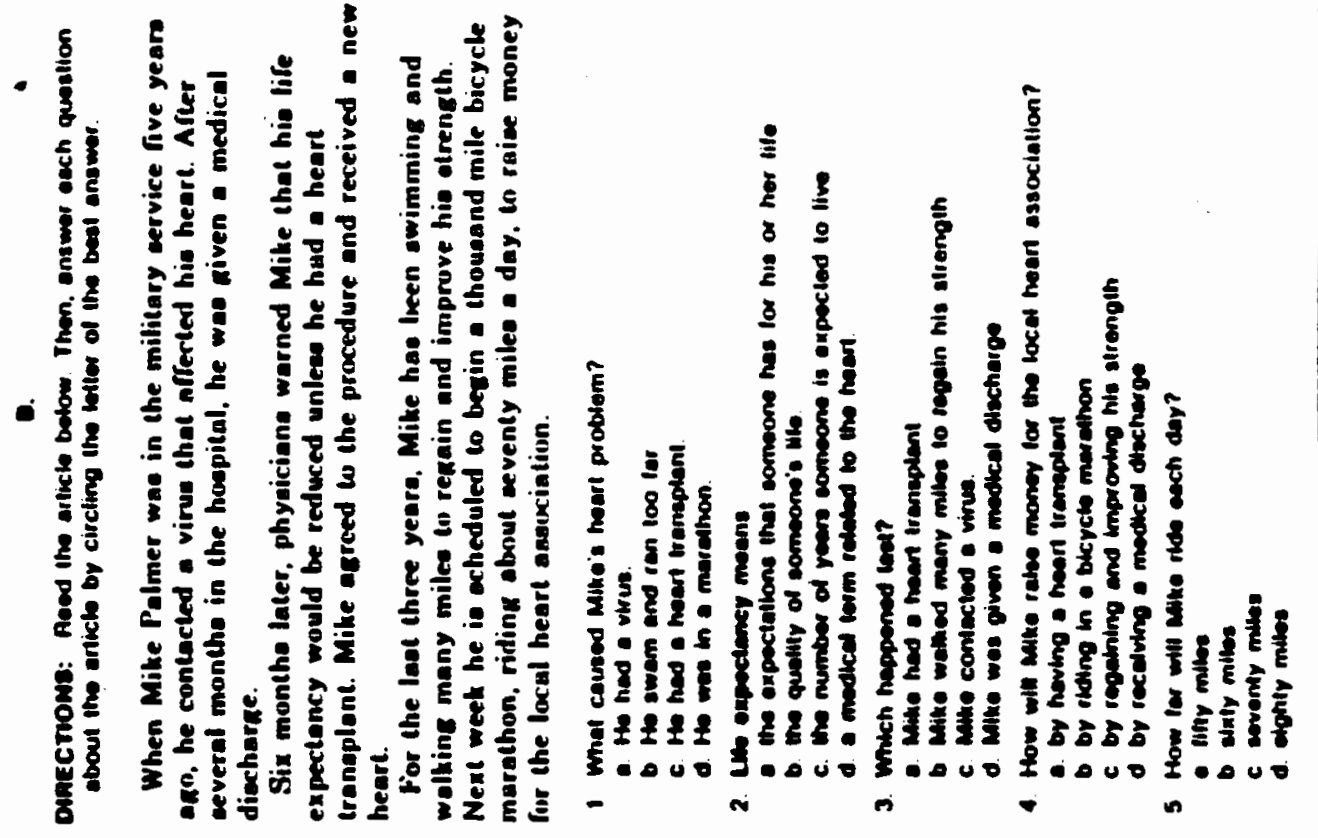

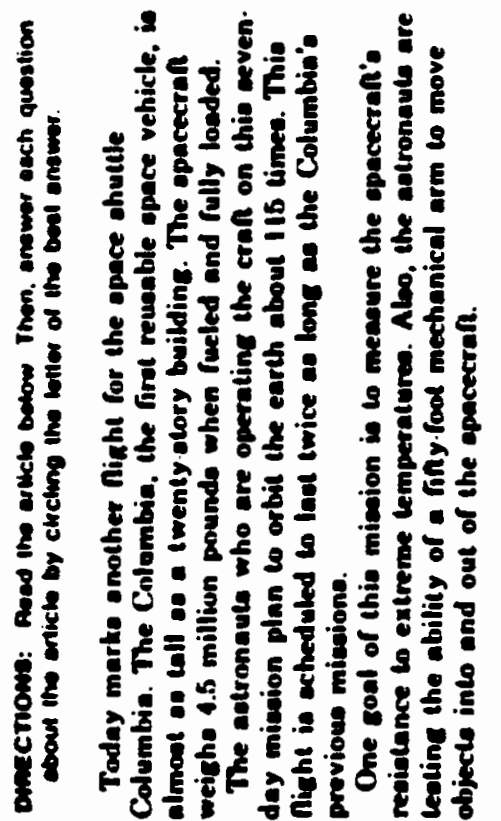

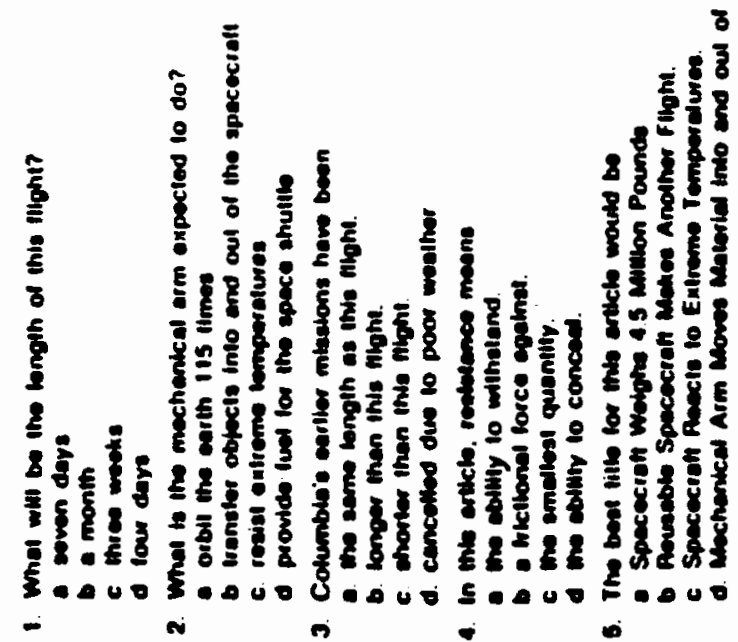


APPENDIX E

DEMOGRAPHIC SURVEY 
Age

Sex (M) or (F) Circle one.

What was the last grade you finished in school?

What grade in school did your parents finish? Mother

Father

Do you work? (yes) or (no) circle one.

If you work, what kind of work do you do?

If you work, do you work part time or full time?
(part time)
20 hours a week or less.
(full time)
40 hours a week or more. 
APPENDIX $F$

INFORMED CONSENT 
INFORMED CONSEKT

I. agree to participate in the research project investigating reading comprehension and self estecen conducted by Judy Heumann.

I understand that this study involves:

(1) attending the ABE class at Portland Comunity College at SE Center. Monday through Friday from 9:00 to 12:00 at least 60x of the Fall term. 1989.

(2) taking the 8rigance reading comprehension test and the Tennessee self Concept Scale at the beginning and at the end of the term.

(3) filling out a demographic survey which will ask about ny age, sex, last grade of school completed and whether I work.

It has been explained to me that the purpose of the study is to learn if there is a relationship betwen how a person feels about hte or herself and how much their reading improves.

I may not recelve any dfrect benefit from particioation in this study but my particlpation may help teachers in the future to know wore about teaching adults how to read.

Judy has offered to answer any questions I may have about the study and what I need to do for her study. I understand that all information I give will be kept confidential and that ay naen will not be used.

I understand that I an free to not partictpate in this study at any time. If I chose not to participate, this will not affect ay status as a student in this class. If I decide not to participate, then I can turn in the study materials unmarked.

I have read and I understand this information.

Date Signature

If you have problems due to participation in this study, please contact the secretary of the Kuan Subjects Research and Revtew Comittee, Office of Grants and Contracts, 303 Cramer Hall, Portland State University, 464-3417. 